\title{
The coordination behaviour of large natural bite angle diphosphine ligands towards methyl and 4-cyanophenylpalladium(II) complexes $\uparrow$
}

\author{
Martin A. Zuideveld, ${ }^{a}$ Bert H. G. Swennenhuis, ${ }^{a}$ Maarten D. K. Boele, ${ }^{a}$ Yannick Guari, ${ }^{a}$ \\ Gino P. F. van Strijdonck, ${ }^{a}$ Joost N. H. Reek, ${ }^{a}$ Paul C. J. Kamer, ${ }^{a}$ Kees Goubitz, ${ }^{b}$ Jan Fraanje, ${ }^{b}$ \\ Martin Lutz, ${ }^{c}$ Anthony L. Spek ${ }^{c}$ and Piet W. N. M. van Leeuwen *a \\ ${ }^{a}$ Institute of Molecular Chemistry, Universiteit van Amsterdam, Nieuwe Achtergracht 166, \\ 1018 WV Amsterdam, The Netherlands.E-mail: pwnm@science.uva.nl \\ ${ }^{b}$ Dept. Crystallography, Universiteit van Amsterdam, Nieuwe Achtergracht 166, \\ 1018 WV Amsterdam, The Netherlands \\ ${ }^{c}$ Bijvoet Center for Biomolecular Research, Dept Crystal and Structural Chemistry, \\ Utrecht University Padualaan 8, 3584 CH Utrecht, The Netherlands
}

Received 20th December 2001, Accepted 11th March 2002

First published as an Advance Article on the web 2nd May 2002

\begin{abstract}
The structures of neutral and ionic 4-cyanophenylpalladium(II) and methylpalladium(II) complexes containing bidentate phosphine ligands were investigated in solution and in the solid state. Diphosphine ligands with a xanthene and a ferrocene backbone were used. New bis(dialkylphosphino) substituted Xantphos ligands were synthesised. ${ }^{1} \mathrm{H}$ NMR and ${ }^{31} \mathrm{P}$ NMR spectroscopy, conductivity measurements, UV-Vis spectroscopy, and X-ray crystallography were used to elucidate the structures of the complexes. Subtle changes of the phosphine ligands govern the coordination mode of the ligand. A variety of bidentate cis-, and trans-coordination and terdentate $\mathrm{P}-\mathrm{O}-\mathrm{P}, \mathrm{P}-\mathrm{S}-\mathrm{P}$ and $\mathrm{P}-\mathrm{Fe}-\mathrm{P}$ coordination modes of the ligands were observed.
\end{abstract}

\section{Introduction}

Metal complexes containing chelating phosphine ligands are active catalysts for a plethora of important reactions. ${ }^{1}$ The performance of such catalysts is sensitive toward changes in the ligand environment. In general, steric and electronic properties ${ }^{2}$ of a ligand strongly influence the rate, the selectivity and the stability of the catalyst. More recently it has been recognised that the geometry of ligands around the metal centre also influences the rate and selectivity of a reaction considerably. ${ }^{3,4}$

Palladium complexes containing phosphine ligands are known to catalyse important reactions such as carboncarbon $^{5-9}$ and carbon-heteroatom coupling reactions, ${ }^{10}$ allylic substitution reactions, ${ }^{11,12}$ carbonylation and $\mathrm{CO} /$ alkene copolymerisation reactions. ${ }^{13,14}$

Basically, all catalytic coupling reactions using chelating diphosphine ligands proceed via the reaction sequence presented in Scheme 1. Firstly, one of the reactants adds oxidatively to a palladium(o) species, to form a square planar palladium(II) compound. In the next step, a coordination site for the other substrate has to be created. This vacant site can be created via dissociation of one of the phosphine moieties or via dissociation of the anion, $\mathrm{X}^{-}$. After coordination of the second substrate and reductive elimination of the product, the palladium(o) species is regenerated. If $\mathrm{Y}$ is an alkene, as in the Heck reaction, ${ }^{15-18}$ the sequence followed is: insertion, $\beta$-elimination of the product and base-assisted reductive elimination of HX. The reaction pathway depends on the coordinating and chelating properties of the ligand, the coordinating properties of $\mathrm{X}^{-}$, the substrates and the solvent. $\mathrm{Pd}(0)$ species are important intermediates in catalytic reactions (Scheme 1) and have been thoroughly investigated using a wide range of diphosphine ligands. The crystal structures of (L-L)Pd(o)(alkene) complexes show a large range of $\mathrm{P}-\mathrm{Pd}-\mathrm{P}$ angles from

$\dagger$ Electronic supplementary information (ESI) available: rotatable 3-D crystal structure diagrams; synthesis details. See http://www.rsc.org/ suppdata/dt/b1/b111596k/
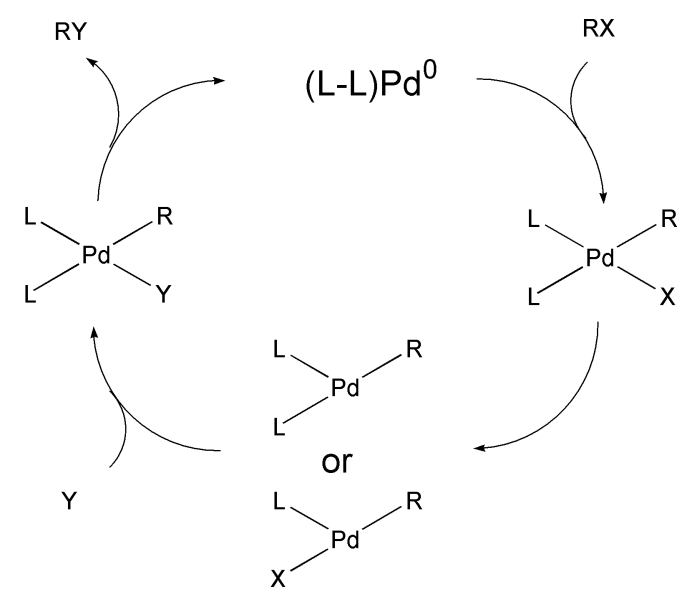

Scheme 1 General catalytic cycle of Pd catalysed coupling reactions.

$84.8^{\circ}$ for (dppe) $\mathrm{Pd}(\mathrm{dba})$ to $115.1^{\circ}$ for $\left(\mathrm{PMe}_{3}\right)_{2} \mathrm{Pd}\left(\eta^{2}-\mathrm{CH}_{2}=\right.$ $\left.\mathrm{CC}_{5} \mathrm{Me}_{4}\right)$, depending on the steric demands of the ligand. ${ }^{19-24}$

The CO/alkene copolymerisation reaction is a reaction that proceeds through $\mathrm{Pd}$ (II) intermediates only. The course of the reaction depends very much on the ligand environment. The use of monodentate ligands such as triphenylphosphine, which forms a trans-complex, leads to the selective formation of methyl propionate. In contrast, the use of cis-chelating diphosphine ligands such as 1,2-bis(diphenylphosphino)ethane (dppe) or 1,3-bis(diphenylphosphino)propane (dppp) produces a high molecular weight copolymer. ${ }^{13,14}$

Recently, our group has developed a series of diphosphine ligands based on xanthene type backbones. ${ }^{25-27}$ These ligands were designed to enforce large phosphorus-metal-phosphorus angles, and have proven to be successful in tuning the activity and selectivity in the palladium catalysed allylic alkylation, ${ }^{28,29}$ cross-coupling reaction, ${ }^{30}$ propionic acid synthesis, ${ }^{31}$ rhodium catalysed hydroformylation, ${ }^{25}$ and the nickel catalysed hydrocyanation of alkenes. ${ }^{32}$ The crystal structures of $\mathrm{Pd}(0)$ - 


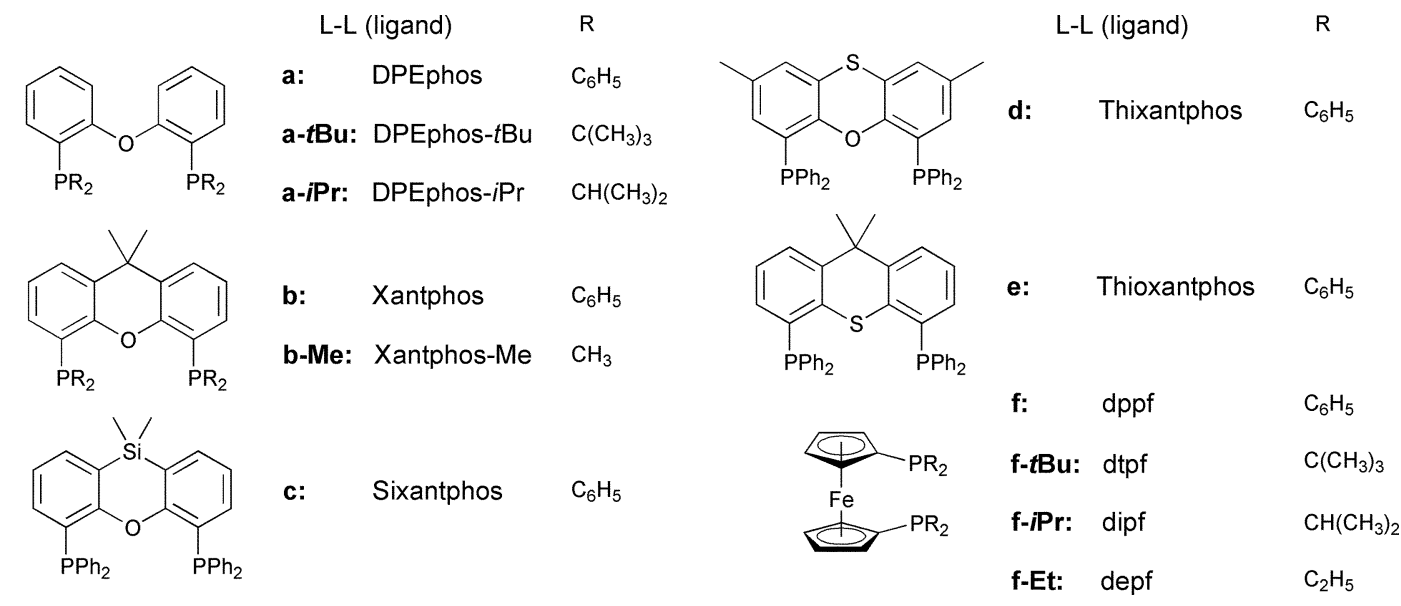

Scheme 2 Ligands used in this study.

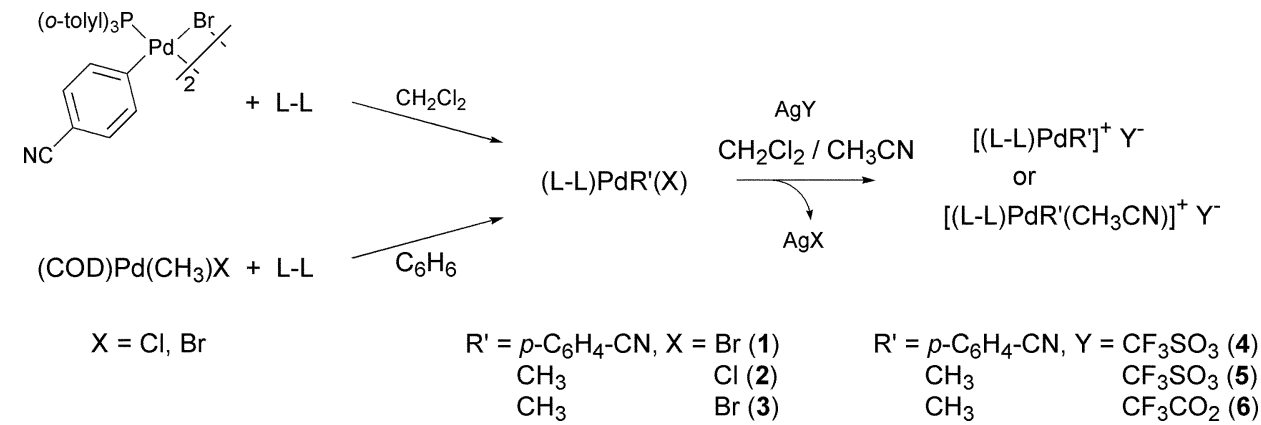

Scheme 3 Synthesis of Pd(diphosphine)-complexes 1-6.

(tetracyanoethylene) complexes containing the DPEphos (a), Sixantphos (c) and Xantphos (b) ligands have been determined. ${ }^{33}$ The widest phosphorus-palladium-phosphorus angle in these zerovalent palladium complexes containing bidentate ligands was found to be $104.6^{\circ}$.

The effects of $\mathrm{Pd}(\mathrm{II})$ complexes containing ligands inducing wide bite-angles based on xanthene and ferrocene backbones on catalysis are not understood completely. Therefore we have rigorously changed the electronic and steric properties of these ligands to study the effects on the geometry of the $\mathrm{Pd}(\mathrm{II}) \mathrm{com}$ plexes. In this study we have systematically investigated neutral and ionic 4-cyanophenylpalladium(II) and methylpalladium(II) complexes in solution and in the solid state. The effects of the diphosphine ligand, the anion and the methyl and 4-cyanophenyl ligands on the structural properties of the palladium complexes is discussed.

\section{Results}

\section{Synthesis}

The syntheses of arylphosphine ligands a-f have been reported previously (a-f, Scheme 2). ${ }^{25,26,34,35}$

Ligands a-tBu and a-iPr were prepared from the reaction of $2,2^{\prime}$-dilithiated diphenyl ether with respectively chlorodi-tertbutylphosphine and chlorodi-iso-propylphosphine. Ligand b-Me was prepared by the reaction of methylmagnesium bromide with 9,9-dimethyl-4,5-bis(dichlorophosphino)xanthene. Attempts to synthesise a ligand containing two tert-butyl groups attached to phosphorus based on the Xantphos backbone failed. Neither by starting from the dilithiated backbone, nor by starting from 9,9-dimethyl-4,5-bis(dichlorophosphino)xanthene could the desired ligand be obtained. Probably steric crowding prevents the coupling of two tert-butyl groups to the same phosphorus.

The neutral complexes ( $\mathrm{L}-\mathrm{L}) \mathrm{Pd}\left(4-\mathrm{C}_{6} \mathrm{H}_{4} \mathrm{CN}\right)(\mathrm{Br}) \quad(\mathrm{L}-\mathrm{L}=$ diphosphine ligand, $\mathbf{1 a}-\mathbf{f})$ are readily synthesised by reaction of $\left\{\left[(o \text {-tolyl })_{3} \mathrm{P}\right] \mathrm{Pd}\left(4-\mathrm{C}_{6} \mathrm{H}_{4} \mathrm{CN}\right) \mathrm{Br}\right\}_{2}$ with two equivalents of the appropriate diphosphine ligand (Scheme 3$).{ }^{36}$

The ionic compounds $\left[(\mathrm{L}-\mathrm{L}) \mathrm{Pd}\left(4-\mathrm{C}_{6} \mathrm{H}_{4} \mathrm{CN}\right)\right]^{+}\left[\mathrm{CF}_{3} \mathrm{SO}_{3}\right]^{-}$(4) were synthesised by salt metathesis of $\mathbf{1}$ in dichloromethane with silver triflate. The presence of a coordinating solvent, such as acetonitrile, was necessary to stabilise the cationic complex $\left[(\mathrm{L}-\mathrm{L}) \mathrm{Pd}\left(4-\mathrm{C}_{6} \mathrm{H}_{4} \mathrm{CN}\right)\left(\mathrm{CH}_{3} \mathrm{CN}\right)\right]^{+}\left[\mathrm{CF}_{3} \mathrm{SO}_{3}\right]^{-}$(4). ${ }^{37}$ Compound 4a is not stable and even in the presence of acetonitrile this complex rapidly decomposes. The other ionic complexes 4 did not need the stabilisation of a coordinating solvent.

Complexes $(\mathrm{L}-\mathrm{L}) \mathrm{Pd}\left(\mathrm{CH}_{3}\right)(\mathrm{Cl})(\mathrm{L}-\mathrm{L}=$ diphosphine ligand, 2) and $(\mathrm{L}-\mathrm{L}) \mathrm{Pd}\left(\mathrm{CH}_{3}\right)(\mathrm{Br})$ (3) were prepared by reaction of $(\mathrm{COD}) \mathrm{Pd}\left(\mathrm{CH}_{3}\right)(\mathrm{Cl})$ and $(\mathrm{COD}) \mathrm{Pd}\left(\mathrm{CH}_{3}\right)(\mathrm{Br})$ with 1.1 equivalents of the appropriate diphosphine ligand (Scheme 3$){ }^{38}$

Ionic complexes $\left[(\mathrm{L}-\mathrm{L}) \mathrm{PdCH}_{3}\right]^{+}[\mathrm{X}]^{-}\left(\mathrm{X}=\mathrm{CF}_{3} \mathrm{SO}_{3}\right.$ (5), $\left.\mathrm{CF}_{3} \mathrm{CO}_{2}(6)\right)$ and $\left[(\mathrm{L}-\mathrm{L}) \mathrm{Pd}\left(\mathrm{CH}_{3}\right)\left(\mathrm{CH}_{3} \mathrm{CN}\right)\right]^{+}[\mathrm{X}]^{-}\left(\mathrm{X}=\mathrm{CF}_{3} \mathrm{SO}_{3}\right.$ (5), $\mathrm{CF}_{3} \mathrm{CO}_{2}(6)$ ) were prepared by abstracting the chloride anion from 2 in dichloromethane-acetonitrile (10:1, v/v) using $\mathrm{AgX}^{38}$

\section{Solution and solid state structures}

In view of the flexible ligand properties a variety of coordination geometries can be envisaged for complexes 1-6 (Scheme 4). To elucidate the structures of the newly synthesised complexes, ${ }^{1} \mathrm{H},{ }^{13} \mathrm{C},{ }^{31} \mathrm{P}$ NMR spectroscopy, X-ray crystallography, UV-Vis spectroscopy and conductivity measurements were performed.

Ligands based on the diphenyl ether backbone. Complex 1a displays an $\mathrm{AB}$ system in the ${ }^{31} \mathrm{P}$ NMR spectra $\left({ }^{2} J_{\mathrm{PP}}=26.7 \mathrm{~Hz}\right)$ which implies that the ligand coordinates in a cis fashion to palladium in solution, similar to previously reported (L-L)$\mathrm{Pd}(\mathrm{Ar})(\mathrm{Br})$ compounds (cis, neutral, Scheme 4). ${ }^{39-45}$ Crystals suitable for X-ray analysis were obtained for compound 1a from $\mathrm{CH}_{2} \mathrm{Cl}_{2}$-hexane (selected data, Table 1). The metal complex has a square planar geometry and the DPEphos ligand in 
Table 1 Selected bond lengths $(\AA)$ and bond angles $\left({ }^{\circ}\right)$ for $(\mathrm{L}-\mathrm{L}) \mathrm{Pd}\left(4-\mathrm{C}_{6} \mathrm{H}_{4} \mathrm{CN}\right) \mathrm{Br}(\mathbf{1 a}-\mathbf{d})$ and $\left[(\mathrm{Xantphos}) \mathrm{Pd}\left(4-\mathrm{C}_{6} \mathrm{H}_{4} \mathrm{CN}\right)\right]^{+}\left[\mathrm{CF}_{3} \mathrm{SO}_{3}\right]^{-}(\mathbf{4 b})$

\begin{tabular}{|c|c|c|c|c|c|}
\hline & 1a & $1 \mathrm{~b}$ & $1 \mathrm{c}$ & $\mathbf{1 d}^{a}$ & $4 b$ \\
\hline Pd-P1 & $2.4141(16)$ & $2.3037(7)$ & $2.2861(16)$ & $2.2794(5)$ & $2.2912(6)$ \\
\hline $\mathrm{Pd}-\mathrm{P} 2$ & $2.2959(17)$ & $2.3167(7)$ & $2.2916(16)$ & $2.2794(5)$ & $2.2816(6)$ \\
\hline $\mathrm{Pd}-\mathrm{Br}$ & $2.4709(9)$ & $2.5339(3)$ & $2.5443(7)$ & $2.5580(3)$ & \\
\hline $\mathrm{Pd}-\mathrm{C} 1$ & $2.0166(6)$ & $2.010(3)$ & $2.006(4)$ & $2.006(3)$ & $1.966(2)$ \\
\hline $\mathrm{Pd}-\mathrm{O}$ & $3.441(4)$ & $2.698(2)$ & 2.714(3) & $2.6957(19)$ & $2.1537(14)$ \\
\hline $\mathrm{C} 1-\mathrm{Pd}-\mathrm{P} 2$ & $88.82(17)$ & $89.73(8)$ & $89.81(14)$ & $91.96(2)$ & $96.26(7)$ \\
\hline $\mathrm{C} 1-\mathrm{Pd}-\mathrm{P} 1$ & $169.81(17)$ & $90.37(8)$ & $89.94(14)$ & $91.96(2)$ & $96.50(7)$ \\
\hline $\mathrm{P} 1-\mathrm{Pd}-\mathrm{P} 2$ & $100.82(6)$ & $150.35(3)$ & $152.15(5)$ & $155.05(2)$ & $165.15(2)$ \\
\hline $\mathrm{C} 1-\mathrm{Pd}-\mathrm{Br}$ & 83.24(16) & $176.12(9)$ & $178.20(15)$ & $179.67(10)$ & \\
\hline $\mathrm{P} 2-\mathrm{Pd}-\mathrm{Br}$ & $164.03(5)$ & $89.76(2)$ & 91.18(4) & 87.97(1) & \\
\hline $\mathrm{P} 1-\mathrm{Pd}-\mathrm{Br}$ & 88.53(4) & $92.076(19)$ & $89.89(4)$ & $87.97(1)$ & \\
\hline $\mathrm{C} 1-\mathrm{Pd}-\mathrm{O}$ & & & & & $177.63(8)$ \\
\hline O-Pd-P2 & & & & & 84.69 \\
\hline $\mathrm{O}-\mathrm{Pd}-\mathrm{P} 1$ & & & & & $83.47(5)$ \\
\hline
\end{tabular}

${ }^{a}$ Compound 1d has crystallographic mirror symmetry.

\begin{tabular}{|c|c|c|c|c|c|}
\hline $\begin{array}{c}X \\
1 \\
P-P d-R \\
P \\
P\end{array}$ & 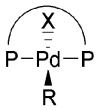 & $\begin{aligned} & \mathrm{NCCH}_{3} \\
& 1 \\
& \mathrm{P}-\mathrm{Pd}-\mathrm{R} \\
& 1 \\
& \mathrm{P}\end{aligned}$ & 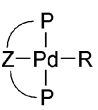 & 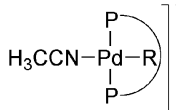 & $\begin{array}{l}\mathrm{R}=\mathrm{CH}_{3}, p-\mathrm{C}_{6} \mathrm{H}_{4}-\mathrm{CN} \\
\mathrm{X}=\text { anion } \\
\mathrm{Z}=\mathrm{O}, \mathrm{S} \text { or } \mathrm{Fe}\end{array}$ \\
\hline $\begin{array}{c}\text { cis } \\
\text { neutral }\end{array}$ & $\begin{array}{c}\text { trans } \\
\text { neutral }\end{array}$ & $\begin{array}{l}\text { cis } \\
\text { ionic }\end{array}$ & $\begin{array}{l}\text { trans } \\
\text { ionic }\end{array}$ & $\begin{array}{c}\text { trans } \\
\text { ionic } \\
\text { (not observed) }\end{array}$ & \\
\hline
\end{tabular}

Scheme 4 Possible geometries for complexes 1-6.

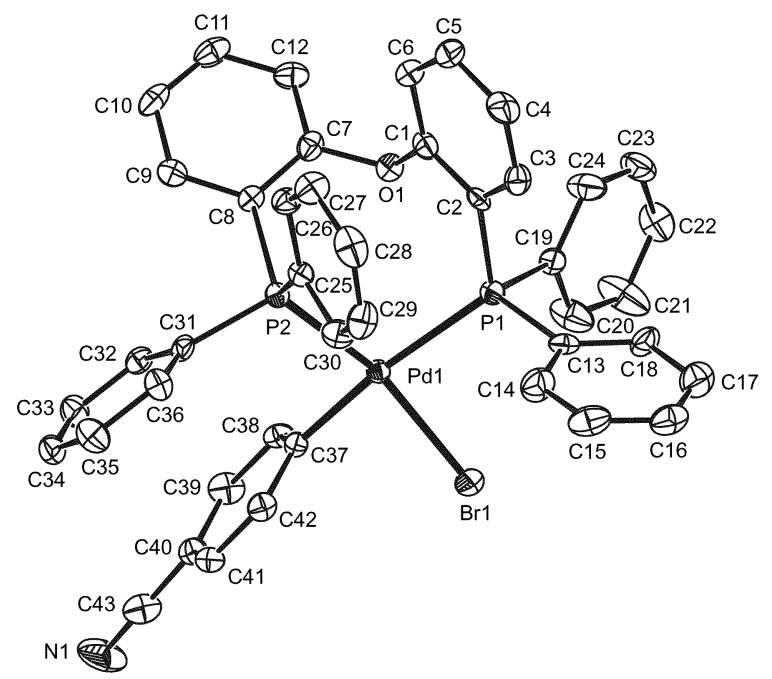

Fig. 1 Displacement ellipsoid plot of 1a. The ellipsoids are drawn at the $50 \%$ probability level. The hydrogen atoms have been omitted for clarity.

this complex is chelated in a cis fashion with a $\mathrm{P}-\mathrm{Pd}-\mathrm{P}$ angle of $100.82(6)^{\circ}$ (Fig. 1). ${ }^{39-45}$

There is no bonding interaction between palladium and the oxygen atom of the backbone $(d(\mathrm{Pd}-\mathrm{O})=3.441(4) \AA)$. The analogous ionic Pd(aryl) complex containing the DPEphos ligand (4a) shows also an $\mathrm{AB}$ system in the ${ }^{31} \mathrm{P}$ NMR spectrum which reflects the $c i s$-coordination. This latter complex, however, decomposes readily, even in the presence of acetonitrile, with formation of palladium metal.

The methyl chloride and methyl bromide complexes $\mathbf{2 a}$ and 3a display a double doublet in the ${ }^{1} \mathrm{H}$ NMR for the methyl group and an $\mathrm{AB}$ system in the ${ }^{31} \mathrm{P}$ NMR spectra. From this it can be concluded that the ligand is coordinating in a cis fashion. Like the ionic arylpalladium complex $\mathbf{4 a}$, the ionic methylpalladium complex 5a, could only be synthesised in the presence of acetonitrile. The presence of a coordinating acetonitrile is confirmed by ${ }^{1} \mathrm{H}$ NMR $(\delta=1.79 \mathrm{ppm})$. The double doublet in the ${ }^{31} \mathrm{P}$ NMR is in accordance with the cis-coordination of the ligand in the ionic complex.
Table 2 Selected bond lengths $(\AA)$ and bond angles $\left(^{\circ}\right)$ for [(DPEphos) $\left.\mathrm{Pd}\left(\mathrm{CH}_{3}\right)\left(\mathrm{CH}_{3} \mathrm{CN}\right)\right]^{+}\left[\mathrm{CF}_{3} \mathrm{SO}_{3}\right]^{-}$(5a) and (DPEphos) $\mathrm{PdCH}_{3}-$ $\left(\mathrm{CF}_{3} \mathrm{CO}_{2}\right)(6 a)$

\begin{tabular}{lclc}
\hline 5a & & & \\
& & & \\
Pd-P1 & $2.443(2)$ & Pd-P2 & $2.241(2)$ \\
Pd-O1 & $3.548(5)$ & Pd-C1 & $2.076(11)$ \\
Pd-N & $2.085(8)$ & & \\
& & & \\
C1-Pd-P2 & $83.1(3)$ & P1-Pd-P2 & $103.24(7)$ \\
C1-Pd-P1 & $173.7(3)$ & C1-Pd-N & $84.3(4)$ \\
P1-Pd-N & $89.4(2)$ & P2-Pd-N & $166.9(2)$ \\
& & & \\
\hline 6a & & & \\
& & & \\
\hline Pd-P1 & $2.4008(11)$ & Pd-P2 & $2.2199(12)$ \\
Pd-O1 & $3.531(4)$ & Pd-C1 & $2.092(5)$ \\
Pd-O2 & $2.113(3)$ & & \\
& & & \\
C1-Pd-P2 & $84.88(15)$ & P1-Pd-P2 & $100.90(4)$ \\
C1-Pd-P1 & $173.66(15)$ & P2-Pd-O2 & $83.13(18)$ \\
P1-Pd-O2 & $91.01(10)$ & & $167.90(10)$ \\
\hline
\end{tabular}

Suitable crystals of compound 5a for an X-ray analysis were obtained from $\mathrm{CH}_{2} \mathrm{Cl}_{2}-\mathrm{Et}_{2} \mathrm{O}$ (selected data, Table 2). The metal centre adopts a square planar geometry and the ligand is coordinated in a cis fashion to palladium (Fig. 2). Acetonitrile is coordinated to palladium with a $\mathrm{Pd}-\mathrm{N}$ bond distance of 2.085(8) $\AA$ which is similar to other reported N-Pd(II) bonds. ${ }^{46,47}$ The P-Pd-P angle $\left(103.24(7)^{\circ}\right)$ is larger than that observed for its neutral counterparts 1a $\left(100.82^{\circ}\right)$ and $\mathbf{6 a}$ $\left(100.90^{\circ}\right.$, vide infra). Despite the large bite angle, no out of plane bending is observed for any of the ligands around the metal centre.

The trifluoroacetate complex $\mathbf{6 a}$ is also a cis complex in $\mathrm{CH}_{2} \mathrm{Cl}_{2}$ solution as evidenced by the double doublet in the ${ }^{31} \mathrm{P}$ NMR. In contrast to the complexes with triflate as the counterion, however, this compound is neutral according to conductivity measurements. Apparently, in $\mathrm{CH}_{2} \mathrm{Cl}_{2}$ the trifluoroacetate anion is coordinated to palladium. When $\mathbf{6 a}$ is dissolved in a dichloromethane-acetonitrile mixture, the compound becomes ionic as proven by conductivity measurements. Obviously the 


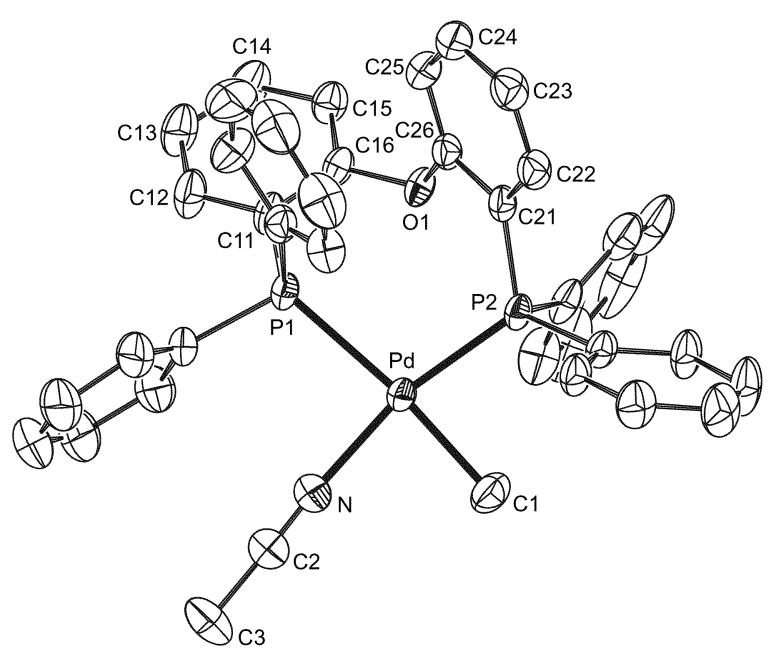

Fig. 2 Displacement ellipsoid plot of 5a. The ellipsoids are drawn at the $50 \%$ probability level. The triflate anion, the non-coordinating solvent molecule and the hydrogen atoms have been omitted for clarity.

acetonitrile ligand assists in the dissociation of the trifluoroacetate anion from the palladium centre to form compound $\mathbf{5 a}$. The coordination of the trifluoroacetate anion is confirmed by $\mathrm{X}$-ray analysis (selected data, Table 2).

The structure of $\mathbf{6 a}$ is very similar to that of 1a. The DPEphos ligand is coordinated $c i s$ to palladium $(\mathrm{P}-\mathrm{Pd}-\mathrm{P}$ angle $=$ $\left.100.90(4)^{\circ}\right)$ and the palladium-phosphorus distances are in the same range. The trifluoroacetate anion is coordinated to palladium via an oxygen atom of the carboxylate group ( $\mathrm{Pd}-\mathrm{O} 2=$ 2.113(3) ̊).

The complexation behaviour of dialkylphosphine substituted DPEphos ligands differs from the diphenylphosphine substituted DPEphos ligand. Complex $\mathbf{2 a - t B u}$, possessing tert-Bu groups at the phosphorus atoms, shows a singlet in the ${ }^{31} \mathrm{P}$ NMR spectrum (48.3 ppm) and a triplet for $\mathrm{PdCH}_{3}$ in the ${ }^{1} \mathrm{H}$ NMR spectrum indicative of a trans-compound $(1.44 \mathrm{ppm}$, ${ }^{3} J_{\mathrm{PH}}=5.1 \mathrm{~Hz}$ ). Complex 5a-tBu showed the same NMR characteristics. Since both compounds $\mathbf{5 a - t B u}$ and $\mathbf{2 a - t B u}$ are ionic according to conductivity measurements, we propose that these complexes contain a palladium-oxygen bond. In contrast, the methylpalladium chloride complex 2a-iPr shows NMR characteristics that are very different from the ionic analogue, 5a-iPr, $v i z$. a singlet in the ${ }^{31} \mathrm{P}$ NMR for the former complex and a double doublet for the latter compound. Furthermore, complex $\mathbf{2 a - i P r}$ is neutral whereas $\mathbf{5 a - i P r}$ is ionic. From this we conclude that in 2a-iPr the ligand is coordinated in a cis fashion, whereas in complex 5a-iPr the ligand is coordinated in a trans fashion and a palladium-oxygen bond is present.

Ligands based on xanthene-type backbones. A broadened singlet in the ${ }^{31} \mathrm{P}$ NMR spectra was observed for compounds 1b-1d at room temperature. An $\mathrm{AB}$ system (minor compound) and a sharp singlet (major compound) appeared at low temperatures $\left(-40{ }^{\circ} \mathrm{C}\right)$. From this observation we concluded that in solution cis-trans isomerisation takes place at room temperature on the NMR time-scale. The cis-trans equilibrium lies at the side of the trans-compound for $\mathbf{1 b}-\mathbf{d}$. Conductivity measurements in dichloromethane solution showed that these complexes are neutral. Crystals of $\mathbf{1 b}-\mathbf{d}$ suitable for an X-ray analysis were obtained from $\mathrm{CH}_{2} \mathrm{Cl}_{2}$-hexane (selected data, Table 1).

In the solid state, complexes $\mathbf{1 b} \mathbf{d}$, show trans-coordination modes (trans, neutral, Scheme 4) with P-Pd-P angles which are in the same range $\left(150.4-155.0^{\circ}, \mathbf{1 b}\right.$, in Fig. 3). The Pd-P distances are similar $(2.28-2.32 \AA)$ and the Pd-O distances $(\approx 2.7$ $\AA$ ) are in the same range as for a five-coordinate palladium complex reported by Cavell et al. ${ }^{48} \mathrm{~A}$ weak $\mathrm{Pd}-\mathrm{O}$ bonding interaction seems to be present. All complexes have a distorted

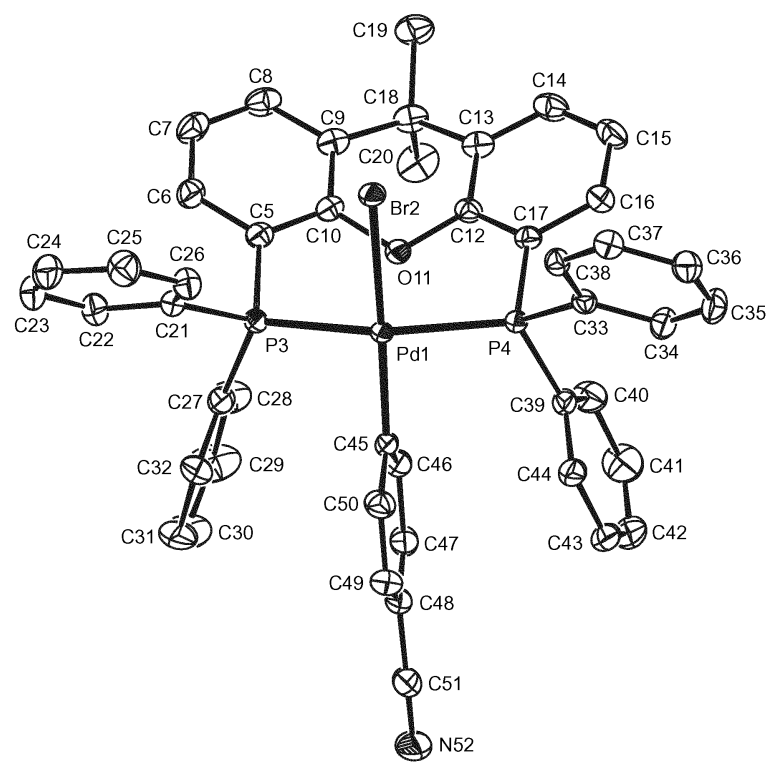

Fig. 3 Displacement ellipsoid plot of $\mathbf{1 b}$. The ellipsoids are drawn at the $50 \%$ probability level. The solvent molecule in $\mathbf{1 b}$ and the hydrogen atoms have been omitted for clarity.

square planar geometry. The complexes are neutral and contain a coordinating bromide anion. The oxygen atom of the ligand backbone is forced into the apical position and the coordinating ability of the oxygen atom is obviously not strong enough to displace the bromide anion to yield an ionic complex. The structures show a slightly elongated $\mathrm{Pd}-\mathrm{Br}$ bond (2.53-2.56 $\mathrm{A}$ ) as compared to the cis compounds ( $\mathrm{Pd}-\mathrm{Br}=2.46-2.47 \AA)$. The dihedral angle between the $\mathrm{P}-\mathrm{O}-\mathrm{P}$ plane and the distorted $\mathrm{Pd}$ square plane is around $77^{\circ}$.

The addition of silver triflate to the cis-trans mixtures resulted in the appearance of one singlet in the ${ }^{31} \mathrm{P}$ NMR spectrum, with a chemical shift different from that of the neutral trans-complexes $\mathbf{1 b}-\mathbf{e}$ described above. The new complexes $\mathbf{4}$ are ionic as proven by conductivity measurements in dichloromethane of the isolated complex. Unlike the synthesis of ionic DPEphos-palladium complexes, the addition of acetonitrile was not necessary to stabilise the cations. The ${ }^{1} \mathrm{H}$ and ${ }^{31} \mathrm{P}$ NMR spectra of the ionic complexes $\mathbf{4}$ did not change when a more polar solvent such as acetonitrile was added to a $\mathrm{CDCl}_{3}$ solution of these compounds. Suitable crystals for an X-ray analysis of $\mathbf{4 b}$ were obtained from $\mathrm{CH}_{2} \mathrm{Cl}_{2}$-hexane (selected data, Table 1). Complex 4b shows a square planar geometry (Fig. 4). In the ionic complex the Xantphos ligand coordinates in the same fashion as 1,8-bis(diphenylphosphino)anthracene. ${ }^{49}$ The phosphorus atoms are trans-coordinated $(\mathrm{P}-\mathrm{Pd}-\mathrm{P}$ angle $=$ $\left.165.15(2)^{\circ}\right)$ and the $\mathrm{Pd}-\mathrm{P}$ distances of both phosphorus atoms are similar $(\mathrm{Pd}-\mathrm{P} 1=2.2912(6)$ and $\mathrm{Pd}-\mathrm{P} 2=2.2816(6) \AA)$. The oxygen atom of the Xantphos ligand is coordinated to the metal centre $(\mathrm{Pd}-\mathrm{O} \text { distance }=2.1537(14) \AA)^{31}$

The methylpalladium complexes containing the xanthene diphosphine ligands $\mathbf{2 b}-\mathbf{d}$ show broad signals in ${ }^{1} \mathrm{H}$ NMR and in ${ }^{31} \mathrm{P}$ NMR spectra at room temperature. At low temperatures (below $-60{ }^{\circ} \mathrm{C}$ ) sharp signals were obtained. The ${ }^{1} \mathrm{H}$ and ${ }^{31} \mathrm{P}$ NMR spectra of $\mathbf{2 d}$ at different temperatures are shown in Fig. 5.

In the ${ }^{31} \mathrm{P}$ NMR spectra at low temperature $\left(-60{ }^{\circ} \mathrm{C}\right)$, complex $\mathbf{2 c}$ shows an AB system only, whereas complexes $\mathbf{2 d}, \mathbf{2 b}$ and 3b show an AB system (major compound) and a singlet. The ${ }^{1} \mathrm{H}$ NMR spectra show a double doublet and a triplet for the methyl group bonded to palladium. The integration ratio of the $\mathrm{AB}$ system and the singlet in the ${ }^{31} \mathrm{P}$ NMR spectra match the double doublet to triplet ratio in the ${ }^{1} \mathrm{H}$ NMR spectra. The chemical shifts of singlets of these compounds do not match with the shifts of the analogous ionic compounds $\mathbf{5 b}-\mathbf{d}$ (vide infra). Furthermore, compounds $\mathbf{2 c}$ and $\mathbf{2 d}$ did not show 


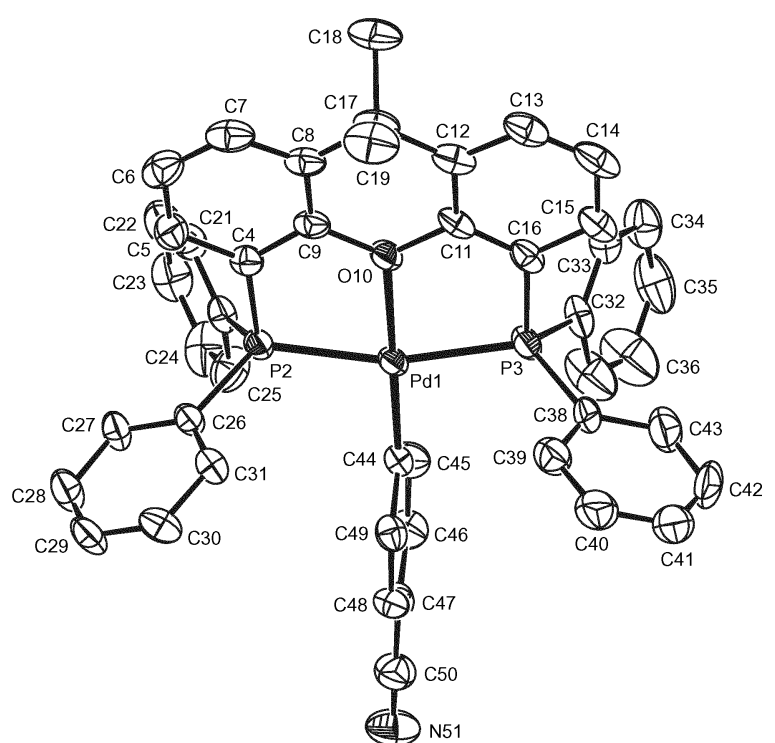

Fig. 4 Displacement ellipsoid plot of $\mathbf{4 b}$. The ellipsoids are drawn at the $50 \%$ probability level. The triflate anion, the solvent molecule and the hydrogen atoms have been omitted for clarity.

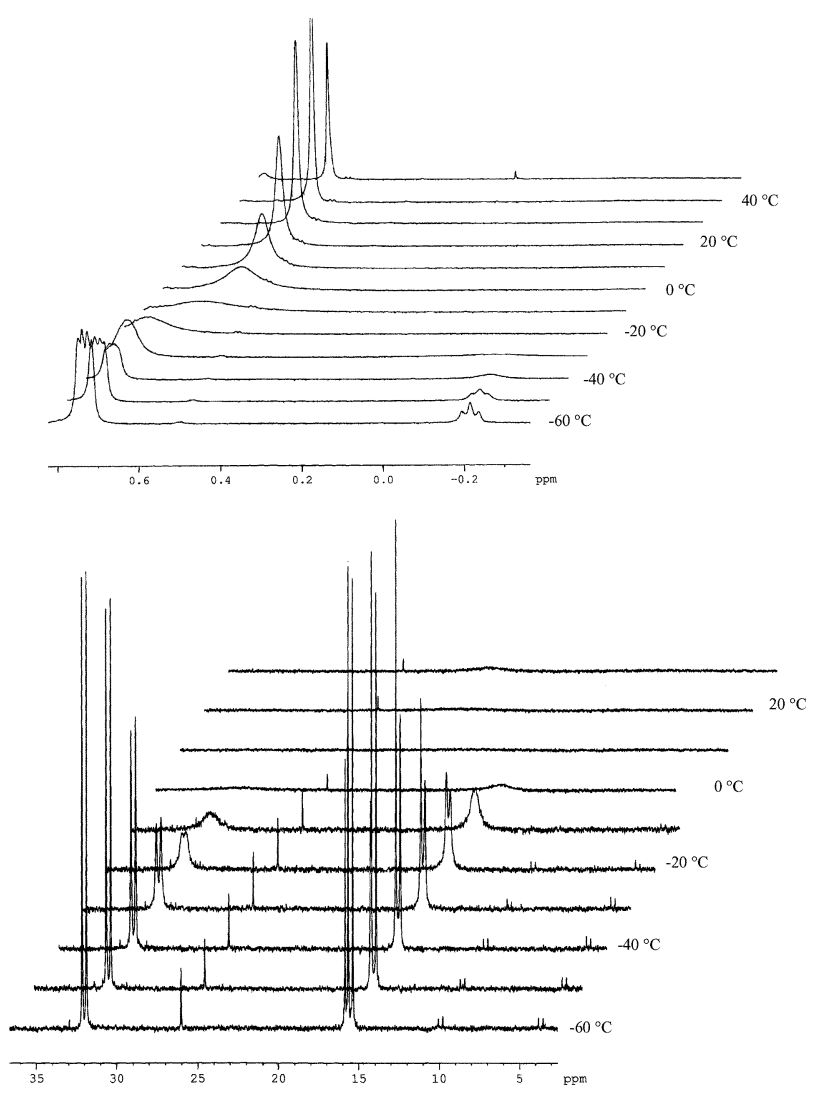

Fig. 5 Variable temperature ${ }^{1} \mathrm{H}$ and ${ }^{31} \mathrm{P}$ NMR spectra of (Thixantphos) $\mathrm{Pd}\left(\mathrm{CH}_{3}\right) \mathrm{Cl}(\mathbf{2 d})$ in $\mathrm{CDCl}_{3}$ from $-60{ }^{\circ} \mathrm{C}$ to $+40{ }^{\circ} \mathrm{C}$.

conductivity in $\mathrm{CH}_{2} \mathrm{Cl}_{2}$. In contrast, the Xantphos complexes $\mathbf{2 b}$ and $\mathbf{3 b}$, showed a molar conductivity of 3.5 and $4.6 \mathrm{~S} \mathrm{~cm}^{-2}$ $\mathrm{mol}^{-1}$ respectively. Based on this, we assign the signals to the neutral, cis and the neutral, trans complexes (Scheme 4).

The effect of changing the temperature on the ratio of ciscompound over trans-compound could only be investigated over a narrow temperature range $\left(-90\right.$ to $\left.-50{ }^{\circ} \mathrm{C}\right)$ due to linebroadening in the NMR spectra. Over this temperature range, the ratios do not change.

The complex with the bromide anion, $\mathbf{3 b}$, contains a larger amount of the trans-compound than the chloride complex, $\mathbf{2 b}$ (cis : trans $=0.90(\mathbf{3 b}), 0.52(\mathbf{2 b})$. When $\mathbf{3 b}$ was dissolved in a
Table 3 Selected bond lengths $(\AA)$ and bond angles $\left({ }^{\circ}\right)$ for (Xantphos)$\mathrm{Pd}\left(\mathrm{CH}_{3}\right) \mathrm{Cl}(\mathbf{2 b})$

\begin{tabular}{lcll} 
2b & & & \\
\hline Pd-P1 & $2.2949(16)$ & Pd-P2 & $2.2916(15)$ \\
Pd-Cl & $2.4290(15)$ & Pd-C1 & $2.107(7)$ \\
& & & \\
Pd-O & $2.658(4)$ & P1-Pd-P2 & $152.61(6)$ \\
C1-Pd-P2 & $91.39(19)$ & C1-Pd-Cl & $174.85(19)$ \\
C1-Pd-P1 & $92.02(19)$ & P2-Pd-Cl & $90.20(5)$ \\
P1-Pd-Cl & $88.82(5)$ & & \\
\hline
\end{tabular}

mixture of $\mathrm{CD}_{2} \mathrm{Cl}_{2}$ and $\mathrm{CD}_{3} \mathrm{CN}$ the equilibrium shifted towards the cis-complex. The signals in the ${ }^{31} \mathrm{P}$ NMR spectra broaden upon addition of $\mathrm{CD}_{3} \mathrm{CN}$. Lowering the temperature of the solution results in a sharpening of the signals.

Suitable crystals of $\mathbf{2 b}$ for X-ray analysis were obtained from $\mathrm{CH}_{2} \mathrm{Cl}_{2}-\mathrm{Et}_{2} \mathrm{O}$ (selected data, Table 3) The structure of $\mathbf{2 b}$ is similar to compounds $\mathbf{1 b}-\mathbf{1 d}$. The metal centre adopts a square planar geometry, and the ligand coordinates in a trans fashion $\left(\mathrm{P}-\mathrm{Pd}-\mathrm{P}\right.$ angle $=152.61(6)^{\circ}$, Table 3$)$. The palladiumphosphorus distances are of the same magnitude (Pd-P1 = 2.2949(16) and $\mathrm{Pd}-\mathrm{P} 2=2.2916(15) \AA$ ).

Palladium complexes containing the Thioxantphos ligand, $\mathbf{e}$ are different from the ligands containing oxygen in their ligand backbone. Compound 1e shows a singlet in the ${ }^{31} \mathrm{P}$ NMR spectrum both at $25^{\circ} \mathrm{C}$ and $-60{ }^{\circ} \mathrm{C}$. The addition of silver triflate to 1e did not lead to a change in chemical shift of the singlet, which suggests that the bromide complex is already ionic. The methylpalladium complexes show a similar behaviour. Complex 2e gives a singlet in the ${ }^{31} \mathrm{P}$ NMR spectrum $(40.5 \mathrm{ppm})$ and a triplet for $\mathrm{PdCH}_{3}$ in the ${ }^{1} \mathrm{H}$ NMR spectrum $\left(1.08 \mathrm{ppm},{ }^{3} J_{\mathrm{PH}}=\right.$ $8.5 \mathrm{~Hz}$ ) at room temperature, indicative of a trans-complex. The NMR spectra did not change when silver triflate was added to a solution of $2 \mathrm{e}$ in $\mathrm{CDCl}_{3}$. The Thioxantphos complexes 1e, and 2e have a molar conductivity in the same range as the ionic complexes, showing that the bromide and chloride anion are substituted by the sulfur donor atom in the ligand backbone. Compound $\mathbf{2 b}-\mathbf{M e}$ is a pure cis-complex according to the $\mathrm{AB}$ system in the ${ }^{31} \mathrm{P}$ NMR spectrum $(-9.0 \mathrm{ppm}$ and $-13.5 \mathrm{ppm}, \mathrm{d}$, ${ }^{2} J_{\mathrm{PP}}=34.3 \mathrm{~Hz}$ ). This is confirmed by the double doublet for $\mathrm{PdCH}_{3}\left(0.66 \mathrm{ppm},{ }^{3} J_{\mathrm{PH}}=4.6 \mathrm{~Hz}\right.$ and $\left.{ }^{3} J_{\mathrm{PH}}=7.7 \mathrm{~Hz}\right)$ in the ${ }^{1} \mathrm{H}$ NMR spectrum. The triflate analogue $\mathbf{5 b}-\mathbf{M e}$, however, turned out to be a trans-complex. The singlet in the ${ }^{31} \mathrm{P}$ NMR spectrum $(-5.0 \mathrm{ppm})$, the triplet in the ${ }^{1} \mathrm{H}$ NMR spectrum $(1.21 \mathrm{ppm}$, ${ }^{3} J_{\mathrm{PH}}=6.6 \mathrm{~Hz}$ ) and the high molar conductivity confirm that this is a trans compound and presumably contains a $\mathrm{Pd}-\mathrm{O}$ bond analogous to $\mathbf{2 b}$.

Ligands based on the ferrocene-type backbones. Previous studies showed that dppf behaves generally as a cis-coordinating ligand in methylpalladium(II) compounds. ${ }^{38}$ We studied the complexation behaviour of dialkylphosphine substituted ferrocene ligands in methylpalladium(II) complexes. All compounds containing ligand f-tBu (1,1'-bis(di-tert-butylphosphino)ferrocene), compounds $\mathbf{2 f - t B u}, 5 \mathbf{5 f - t B u}$ and $\mathbf{6 f - t B u}$, yield complexes which show a singlet in the ${ }^{31} \mathrm{P}$ NMR spectra $(29.3$ ppm) and a triplet in the ${ }^{1} \mathrm{H}$ NMR spectra for the $\mathrm{PdCH} \mathrm{H}_{3}$ group $\left(1.70 \mathrm{ppm},{ }^{3} J_{\mathrm{PH}}=4.8 \mathrm{~Hz}\right){ }^{50}$ These observations support a transgeometry of the ligand in these complexes. The large chemical shift difference between the $\alpha$ and the $\beta$ hydrogen atoms of the cyclopentadienyl rings in the complexes (1.0-1.3 ppm) in comparison with the differences in the free ligand $(0.14 \mathrm{ppm})$ indicate that these rings are slightly tilted. ${ }^{51}$ Such NMR characteristics indicate that an interaction between palladium and iron is present in solution. UV-Vis spectra, however, showed only one absorption around $349 \mathrm{~nm}$, absorptions at higher wavelengths, typical of $\mathrm{Pd}-\mathrm{Fe}$ interactions, ${ }^{51}$ were not observed.

Crystals of $\mathbf{5 f - t B u}$ suitable for an X-ray analysis were obtained from $\mathrm{CH}_{2} \mathrm{Cl}_{2}-\mathrm{Et}_{2} \mathrm{O}$ (selected data, Table 4). The metal 
Table 4 Selected bond lengths $(\AA)$ and bond angles $\left(^{\circ}\right)$ for [(dtpf)$\left.\mathrm{PdCH}_{3}\right]^{+}\left[\mathrm{CF}_{3} \mathrm{SO}_{3}\right]^{-}(\mathbf{5 f}-\mathbf{t B u})$

\begin{tabular}{lrlr}
\hline 5f-tBu & & & \\
\hline Pd-P1 & $2.2862(5)$ & Pd-P2 & $2.2979(5)$ \\
Pd-Fe & $3.0683(3)$ & Pd-C1 & $2.035(3)$ \\
& & & \\
P-Pd-P & $158.21(2)$ & P2-Pd-C1 & $100.65(7)$ \\
C1-Pd-P1 & $100.76(7)$ & P2-Pd-Fe & $79.47(1)$ \\
P1-Pd-Fe & $79.19(1)$ & Fe-Pd-C1 & $178.97(8)$ \\
\hline
\end{tabular}

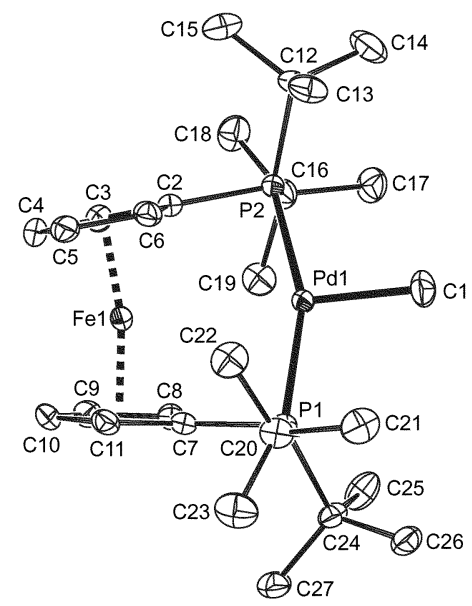

Fig. 6 Displacement ellipsoid plot of $\mathbf{5 f - t B u}$. The ellipsoids are drawn at the $50 \%$ probability level. The triflate anion and the hydrogen atoms have been omitted for clarity.

centre in $\mathbf{5 f - t B u}$ adopts a square planar geometry (Fig. 6). Like the Xantphos ligand in $\mathbf{4 b}$ (vide supra), the ferrocene ligand in 5f-tBu behaves as a terdentate ligand. The phosphorus atoms are trans-coordinated $\left(\mathrm{P}-\mathrm{Pd}-\mathrm{P}\right.$ angle $\left.=158.21(2)^{\circ}\right)$ and the iron atom of the ligand backbone has a weak interaction with the palladium centre $(\mathrm{Pd}-\mathrm{Fe}$ distance $=3.0683(3) \AA)$. $\mathrm{Pd}-\mathrm{Fe}$ bonds were found previously in dicationic complexes, ${ }^{51,52}$ but this is the first example of a monocationic methylpalladium compound with a palladium-iron bond. The interatomic $\mathrm{Pd}-\mathrm{Fe}$ distance in complex $\mathbf{5 f - t B u}$ is larger than other $\mathrm{Pd}-\mathrm{Fe}$ bonds, such as $\left[(\mathrm{dppf}) \mathrm{Pd}\left(\mathrm{PPh}_{3}\right)\right]\left[\mathrm{BF}_{4}\right]_{2}(2.88 \AA)^{51}$ and [(1,5,9-trithia[9] ferrocenophane) $\left.\mathrm{Pd}\left(\mathrm{CH}_{3} \mathrm{CN}\right)\right]\left[\mathrm{BF}_{4}\right]_{2}(2.83 \AA)^{52}$ which have been reported by Sato et al., but it is in the same range as that in $\left[(1,4,7\right.$-trithia[7]ferrocenophane $\left.) \mathrm{Pd}\left(\mathrm{CH}_{3} \mathrm{CN}\right)\right]\left[\mathrm{BF}_{4}\right]_{2}(3.10 \AA) .{ }^{52}$ The $\mathrm{Pd}-\mathrm{P}$ distances are in the range generally found for transcoordinating phosphorus atoms (e.g. complexes $\mathbf{1 c}-\mathbf{e}$ and $\mathbf{4 b}$ $(\mathrm{Pd}-\mathrm{P} 1=2.2862(5)$ and $\mathrm{Pd}-\mathrm{P} 2=2.2979(5) \AA)$ ).

The complexes containing ligand f-iPr $\left(1,1^{\prime}\right.$-bis(di-isopropylphosphino)ferrocene) show NMR characteristics that are similar to those of the dppf ligand, $\mathbf{f}$. The ionic complex $\mathbf{5 f}$ iPr shows an AB system in the ${ }^{31} \mathrm{P}$ NMR spectrum (54.1 and $32.7 \mathrm{ppm},{ }^{2} J_{\mathrm{PP}}=21.3 \mathrm{~Hz}$ ) and a double doublet in the ${ }^{1} \mathrm{H}$ NMR spectrum for $\mathrm{PdCH}_{3}\left(0.73 \mathrm{ppm},{ }^{3} J_{\mathrm{PH}}=4.8 \mathrm{~Hz}\right.$ and $\left.{ }^{3} J_{\mathrm{PH}} \approx 1 \mathrm{~Hz}\right)$. According to ${ }^{1} \mathrm{H}$ NMR spectroscopy, acetonitrile is coordinated to the palladium centre. The singlet in the ${ }^{31} \mathrm{P}$ NMR spectrum $(4.5 \mathrm{ppm})$ for the methylpalladium chloride complex 7 (ligand f-Et), the triplet for $\mathrm{PdCH}_{3}\left(0.51 \mathrm{ppm},{ }^{3} J_{\mathrm{PH}}=5.9 \mathrm{~Hz}\right)$ in the ${ }^{1} \mathrm{H}$ NMR spectrum and the large chemical shift differences between the $\alpha$ and $\beta$ hydrogen atoms of the cyclopentadienyl rings in the complex $(0.75 \mathrm{ppm})$, suggest a similar coordination as observed for complex 2f-tBu. Molecular weight determination in solution, however, showed that 7 is a dimeric compound. When a solution of 7 was allowed to stand at room temperature in $\mathrm{CD}_{2} \mathrm{Cl}_{2}$, a slow reaction occured. $\mathrm{A}$ new $\mathrm{AB}$ system appeared in the ${ }^{31} \mathrm{P}$ NMR spectrum $(30.1$ and $10.7 \mathrm{ppm}$, ${ }^{2} J_{\mathrm{PP}}=28.2 \mathrm{~Hz}$ ) and a double doublet for the methyl group appeared in the ${ }^{1} \mathrm{H}$ NMR $\left(0.75 \mathrm{ppm},{ }^{3} J_{\mathrm{PH}}=7.5 \mathrm{~Hz}\right.$ and ${ }^{3} J_{\mathrm{PH}}=$
3.6 Hz). Molecular weight determination in solution showed that the new compound, $\mathbf{8}$, is a monomeric cis-compound analogous to $\mathbf{2 f}$ and $\mathbf{2 f - i P r}$.

\section{Discussion}

Neutral complexes containing the DPEphos ligand are ciscoordinated and show no sign of a palladium-oxygen interaction, irrespective of the other coordinating groups. This may be caused by the preference of the DPEphos ligand for a smaller bite angle than the other ligands in the Xantphosseries. ${ }^{25,53}$ Ionic complexes containing the DPEphos ligand need a coordinating solvent to stabilise the ionic metal centre. Only at low temperatures was the cation possessing a palladiumoxygen bond observed. In the absence of coordinating solvents DPEphos has the tendency to form a palladium-oxygen bond, which shows the strength of such a bonding interaction and the capability of the ligand to coordinate in a trans-fashion. The crystal structures of complexes with the DPEphos ligand show that the two phenyl rings of the ligand backbone can rotate around the carbon-oxygen bond. One of the phenyl rings of the ligand backbone has a $\pi-\pi$ interaction with one of the phenyl rings bonded to the phosphorus atom. Similar interactions have been reported before in MeO-Biphep metal complexes. ${ }^{54}$ The bulkiness of the substituents on the phosphorus atoms is important. tert-Butyl groups on phosphorus (ligand atBu) probably destabilise the cis complex, thus forcing the complex to an ionic trans complex containing a palladium-oxygen bond. The cis-complexes cannot be formed due to steric crowding around the metal centre. This is confirmed by the less crowded iso-propyl substituted ligand, a-iPr, which indeed coordinates in a cis-fashion. The strength of the palladiumoxygen bond is illustrated by the fact that in the methyl-

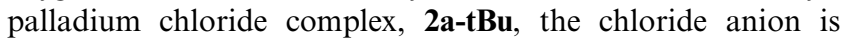
displaced from the metal centre.

The solid state structures of complexes $\mathbf{1 b}-\mathbf{d}$ and $\mathbf{2 b}$, which contain ligands having large bite angles, show that the oxygen atom of the $\mathrm{P}-\mathrm{O}-\mathrm{P}$ ligand backbone in the trans-complexes is located at the apical position of the square pyramidal complex. The weak palladium-oxygen interaction can stabilise the transcomplex relative to the cis-complex, which lacks such a bonding interaction. Equilibrium mixtures of the arylpalladium complexes (1b-d) in solution consist mainly of the trans-complex, whereas the methylpalladium complexes (2b-d) are mainly ciscoordinated complexes. Three reasons can account for these observations. The more electron-withdrawing aryl group results in less electron density at the metal centre. The apical oxygen atom will therefore coordinate more strongly in the arylpalladium complex 1 than in the more electron rich methylpalladium complex 2 . Furthermore, the $\pi-\pi$ interaction between the phenyl groups on phosphorus and the aryl group attached to the palladium centre can stabilise the trans-complex relative to the cis-complex, as such an interaction is absent in methylpalladium complexes. In cis-complexes the phenyl rings bonded to phosphorus cannot be oriented in such a way that a $\pi-\pi$ interaction with the 4-cyanophenyl group is possible due to the rigidity of the ligand backbone. The methylpalladium complexes lack such a stabilisation and therefore are mainly present as cis-complexes. A second difference between the methylpalladium complexes $\mathbf{2}$ and the arylpalladium complexes $\mathbf{1}$ are the halogen ligands. The methylpalladium complexes contain chloride ligands, the arylpalladium complexes bromide ligands. A cis-coordination of the diphosphine ligand would be relatively more stabilised in complexes containing the smaller chloride ligands than in complexes containing the larger bromide ligands.

The alkylphosphine ligand b-Me forms a cis-complex only. The higher electron density on palladium makes a bonding palladium-oxygen interaction less favourable and therefore the trans-complex is not observed. 
Another possible effect of the proximity of the oxygen atom to the palladium centre may be the stabilisation of an ionic intermediate that can be formed during the interchange from the cis- to the trans-complexes (Scheme 5). Only in the case of

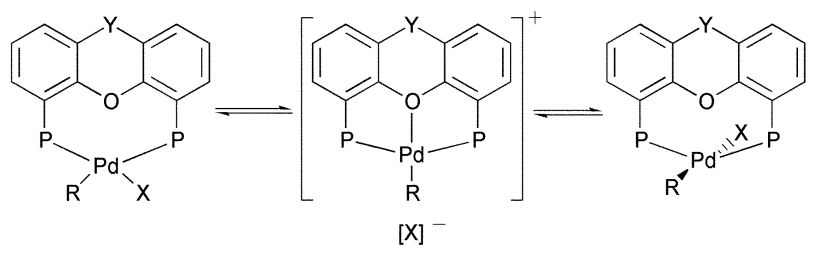

neutral / cis

cationic / trans

neutral / trans

Scheme 5 Possible pathway for cis-trans isomerisation.

complexes $\mathbf{2 b}$ and $\mathbf{3 b}$ could a significantly higher conductivity be measured, which would suggest the presence of such an ionic intermediate; this could, however, not be verified using NMR spectroscopy. The addition of a more polar co-solvent (acetonitrile) to a solution of $\mathbf{3 b}$ in dichloromethane led to an increase of the amount of cis-complex. The polar solvent stabilises the more polar cis-complex. The rate of interconversion between the cis- and trans-complexes was higher in the more polar solvent, which could be caused by the stabilisation of the ionic intermediate (Scheme 5). The molar conductivities of complex 1e and $\mathbf{2 e}$ are of the same magnitude as that of the complexes with triflate as the counter-ion, which means that the bromide and chloride anion are not coordinated to the metal centre. In these complexes the bromide and chloride anions are substituted by the sulfur ligand of the ligand backbone. ${ }^{55}$ The soft sulfur atom can displace the coordinated anions, since it can bind more strongly to the soft palladium metal centre than the hard oxygen atom. Addition of acetonitrile or coordinating anions (chloride or bromide anions) to solutions of ionic complexes having a $\mathrm{Pd}-\mathrm{O}$ or $\mathrm{Pd}-\mathrm{S}$ bond did not affect the structure of the complexes. Such additives apparently cannot compete with the intramolecular $\mathrm{Pd}-\mathrm{O}$ and $\mathrm{Pd}-\mathrm{S}$ bonds.

It has been shown that the iron atom of dppf can coordinate to palladium and that these complexes which contain a palladium-iron bond are generally strongly coloured. ${ }^{51,52}$ The complexes described in this study, however, are not strongly coloured and in the visible range no other absorptions were observed than those originating from the ferrocene unit. The solid state structure of $\mathbf{5 f - t B u}$ has been determined and this clearly shows the existence of a palladium-iron interaction, but the NMR spectra of $\mathbf{2} \mathbf{f}-\mathbf{t B u}$ and $\mathbf{6 f -}-\mathbf{t B u}$ show the same characteristics in solution as $\mathbf{5 f - t B u}$. These complexes show a large chemical shift difference between the $\alpha$ and $\beta$ hydrogens of the cyclopentadienyl ligand. The methylpalladium chloride complex $\mathbf{2 f - t B u}$ is ionic in dichloromethane solution, which indicates that the chloride anion is no longer bonded to palladium and the fourth coordination site is probably occupied by iron. These observations indicate that in these complexes a weak Pd$\mathrm{Fe}$ interaction is present as well (Scheme 6). The main difference between the complexes described here and the ones described by Sato, is that the latter complexes are dicationic. The difference in electrophilicity of the palladium centre can account for the differences in the UV-Vis spectra. The bulkiness of the ligand (large tert-butyl groups) hampers a cis-coordination to palladium. Because the phosphorus atoms are positioned trans, the iron atom is forced into the proximity of the palladium centre enforcing the iron-palladium interaction. The slightly less bulky iso-propyl ligand, f-iPr, leads to the normal ciscoordination. No spectroscopic evidence was found for a palladium-iron interaction. The same was observed by Butler et al. in the crystal structure of (dipf) $\mathrm{PdCl}_{2} \cdot{ }^{56}$ The even less bulky substituted diphosphine ligand f-Et yields a different complex again (Scheme 6). The ${ }^{1} \mathrm{H}$ NMR chemical shift difference of the $\alpha$ and $\beta$ hydrogens is large, which indicates that cyclopentadienyl rings are tilted and this suggests the presence of a palladium-iron bonding interaction. In addition, a triplet for the methyl group is observed. The large chemical shift difference between the $\mathrm{PdCH}_{3}$ signals in the ${ }^{1} \mathrm{H}$ NMR spectra (1.70 ppm for $\mathbf{2 f - t B u}$ and $0.51 \mathrm{ppm}$ for 7 ) and the low molar conductivity, indicative of a neutral complex, suggest that a different complex is formed. Molecular weight determination in solution proved that $\mathbf{7}$ is a dimeric compound, analogously to the previously reported compound $\left[(\mathrm{dppm}) \mathrm{Pd}\left(\mathrm{CH}_{3}\right) \mathrm{Cl}\right]_{2} \cdot{ }^{57}$ The formation of a dimer is surprising if we consider that the ligands in compound $\mathbf{2} \mathbf{f}$ and $\mathbf{2 f - i P r},{ }^{38}$ are cis-chelating. The observation of the slow formation of the monomeric ciscomplex, $\mathbf{8}$, in dichloromethane solution provided an answer to this dilemma (Scheme 6) ${ }^{57}$ Obviously, the dimer is formed as the kinetic product during the synthesis in benzene, whereas the cis-complex is the thermodynamically favoured compound.

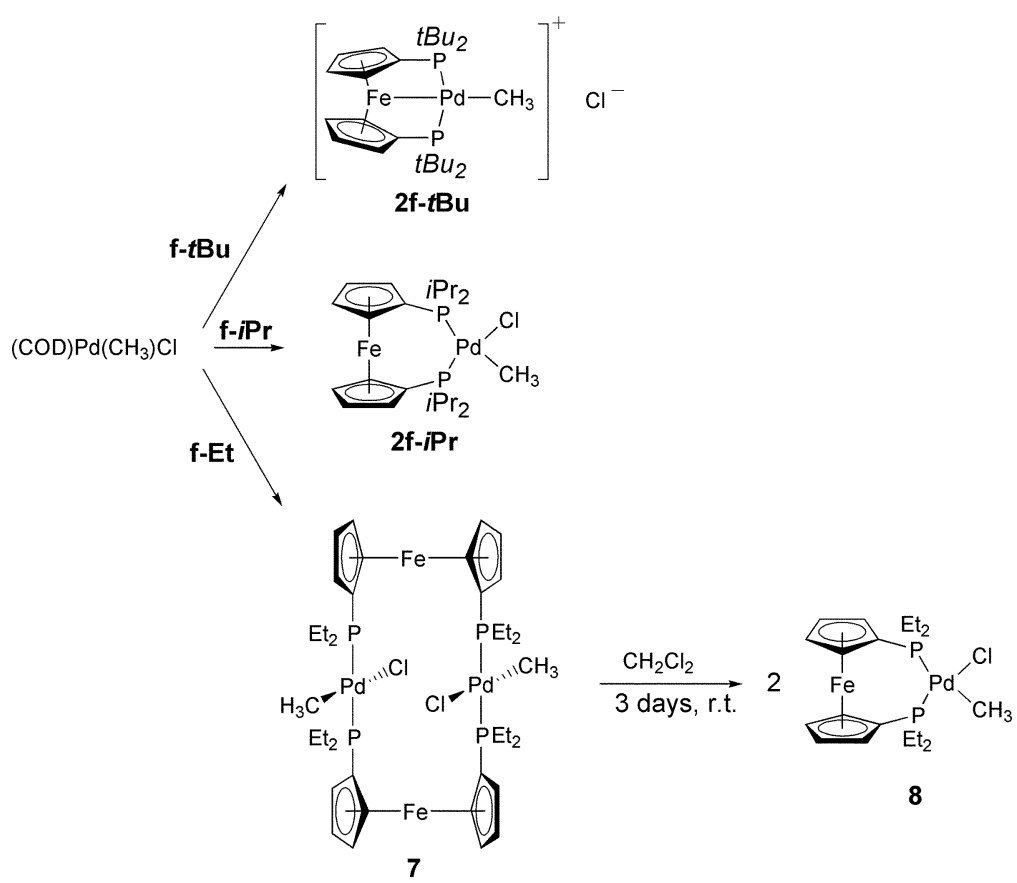

Scheme 6 Synthesis of Pd-complexes using the ligands f-tBu, f-iPr and f-Et. 


\section{Conclusions}

Solid state and solution structures of palladium(II) complexes bearing diphosphine ligands based on the diphenyl ether, xanthene and ferrocene backbone have been studied. Subtle changes in the steric and electronic properties of the diphosphine ligands and the electron density on the palladium metal influence the structure of the palladium complexes dramatically.

\section{Experimental}

\section{Ligand synthesis}

The synthesis of all ligands is described in the ESI.

\section{Complex synthesis}

General remarks. The alkylphosphine ligands used in complex synthesis were used in a larger excess in cases where the ligand had partially oxidised prior to use. The oxidised alkylphosphine ligands did not coordinate to palladium. Palladium complexes containing bidentate alkylphosphine ligands could be handled and stored under ambient conditions.

The detailed syntheses of the complexes are described in the ESI.

Synthesis of ( $\mathrm{L}-\mathrm{L}) \mathrm{Pd}\left(4-\mathrm{C}_{6} \mathrm{H}_{4} \mathrm{CN}\right) \mathrm{Br}$ (1). A solution of $\left\{\left[(o \text {-tolyl })_{3} \mathrm{P}\right] \mathrm{Pd}\left(4-\mathrm{C}_{6} \mathrm{H}_{4} \mathrm{CN}\right) \mathrm{Br}\right\}_{2}(300 \mathrm{mg} ; 0.25 \mathrm{mmol})$ and diphosphine $(0.50 \mathrm{mmol}, 2.0$ equiv. $)$ in dichloromethane $(10$ $\mathrm{mL}$ ) was allowed to react overnight at room temperature. The solution was concentrated in vacuo to $c a .5 \mathrm{~mL}$. Then, $10 \mathrm{~mL}$ of diethyl ether was added which resulted in the formation of orange crystals. The suspension was filtered and the crystals dried in vacuo.

Synthesis of ( $\mathbf{L}-\mathbf{L}) \mathbf{P d}\left(\mathrm{CH}_{3}\right) \mathbf{C l}(\mathbf{2})$. To a solution of $0.36 \mathrm{mmol}$ (COD)Pd $\left(\mathrm{CH}_{3}\right) \mathrm{Cl}$ in $5 \mathrm{~mL}$ of benzene, $0.37 \mathrm{mmol}$ (1.05 equiv.) of ligand $(\mathrm{L}-\mathrm{L})$ was added. The solution was stirred for one hour. The suspension was filtered and the residue was washed with benzene and diethyl ether. The product was dried in vacuo.

Synthesis of (L-L)Pd(CH $\left(\mathbf{C H}_{3}\right) \mathbf{B r}$ (3). To a solution of $0.36 \mathrm{mmol}$ (COD) $\mathrm{Pd}\left(\mathrm{CH}_{3}\right) \mathrm{Br}$ in $5 \mathrm{~mL}$ of benzene, $0.37 \mathrm{mmol}$ (1.05 equiv.) of ligand $(\mathrm{L}-\mathrm{L})$ was added. The solution was stirred for one hour. The suspension was filtered and the residue was washed with benzene and diethyl ether. The product was dried in vacuo.

Synthesis of $\left[(\mathrm{L}-\mathrm{L}) \mathrm{Pd}\left(4-\mathrm{C}_{6} \mathrm{H}_{4} \mathrm{CN}\right)\right]^{+}\left[\mathrm{CF}_{3} \mathrm{SO}_{3}\right]^{-}$and $[(\mathrm{L}-\mathrm{L})-$ $\left.\operatorname{Pd}\left(4-\mathrm{C}_{6} \mathrm{H}_{4} \mathrm{CN}\right)\left(\mathrm{CH}_{3} \mathrm{CN}\right)\right]^{+}\left[\mathrm{CF}_{3} \mathrm{SO}_{3}\right]^{-}$(4). A solution of 1 $(0.18 \mathrm{mmol})$ and silver triflate $(0.18 \mathrm{mmol})$ in $10 \mathrm{~mL}$ of $\mathrm{CH}_{2} \mathrm{Cl}_{2}-\mathrm{CH}_{3} \mathrm{CN}(10: 1$, v/v) was stirred in the dark for one hour. A suspension of Norit in $5 \mathrm{~mL}$ of $\mathrm{CH}_{2} \mathrm{Cl}_{2}$ was added and the reaction mixture was stirred for another hour. The suspension was filtered and the filtrate was concentrated under vacuum to $c a .5 \mathrm{~mL}$. $10 \mathrm{~mL}$ of diethyl ether was added resulting in the formation of colourless crystals. The suspension was filtered and the crystals were dried in vacuo.

Synthesis of ionic methylpalladium complexes (5 and 6). $0.190 \mathrm{mmol} 2$ was suspended in $2 \mathrm{~mL}$ of $\mathrm{CH}_{2} \mathrm{Cl}_{2}-\mathrm{CH}_{3} \mathrm{CN}$ (10: 1, v/v). $0.191 \mathrm{mmol}$ of $\mathrm{AgX}\left(\mathrm{X}=\mathrm{CF}_{3} \mathrm{SO}_{3}, \mathrm{CF}_{3} \mathrm{CO}_{2}\right)$ was added to the suspension. After stirring for 10 minutes, the suspension was filtered over Celite. Then $10 \mathrm{~mL}$ diethyl ether was added to crystallise the product.

\section{Crystallography}

Crystal structure determination of 1a. $\mathrm{C}_{43} \mathrm{H}_{32} \mathrm{BrNOP}_{2} \mathrm{Pd}, \mathrm{FW}$ $=826.95$, yellow needles, $0.25 \times 0.13 \times 0.13 \mathrm{~mm}^{3}$, monoclinic, $P 2_{1} / c$ (no. 14), $a=20.308(2), b=10.5695(19), c=16.309(2) \AA$ $\beta=90.245(9)^{\circ}, V=3500.6(8) \AA^{3}, Z=4, \rho=1.569 \mathrm{~g} \mathrm{~cm}^{-3} .6387$ reflections were measured on an Enraf-Nonius CAD4T diffractometer with a rotating anode $(\lambda=0.71073 \AA)$ at a temperature of $150(2) \mathrm{K} .6143$ reflections were unique $\left(R_{\text {int }}=0.0401\right)$. Absorption correction with PLATON ${ }^{58}$ (DELABS, $\mu=1.799$ $\mathrm{mm}^{-1}, 0.57-0.87$ transmission). Structure solved with Patterson methods (DIRDIF-97) ${ }^{59}$ and refined with SHELXL-97 ${ }^{60}$ against $F^{2}$ of all reflections. Non-hydrogen atoms were refined freely with anisotropic displacement parameters. Hydrogen atoms were refined as rigid groups. 442 refined parameters, no restraints. $R$-values $[I>2 \sigma(I)]: R 1=0.0508, w R 2=0.0840$. $R$-values [all reflections]: $R 1=0.1006, w R 2=0.0988$. Molecular illustration, structure checking and calculations were performed with the PLATON package. ${ }^{58}$

Crystal structure determination of $\mathbf{1 b} . \mathrm{C}_{48} \mathrm{H}_{36} \mathrm{BrNOP}{ }_{2} \mathrm{Pd} \cdot 0.58$ $\mathrm{CH}_{2} \mathrm{Cl}_{2}, \mathrm{FW}=916.27$, red-brown plate, $0.28 \times 0.22 \times$ $0.08 \mathrm{~mm}^{3}$, monoclinic, $P 2_{1} / c$ (no. 14), $a=21.8648(2), b=$ $10.0742(1), c=22.7549(2) \AA, \beta=119.142(1)^{\circ}, V=4377.76(7) \AA^{3}$, $Z=4, \rho=1.390 \mathrm{~g} \mathrm{~cm}^{-3} .78748$ reflections were measured on a Nonius KappaCCD diffractometer with a rotating anode $(\lambda=$ $0.71073 \AA$ ) at a temperature of 150 (2) K. 10040 reflections were unique $\left(R_{\text {int }}=0.0517\right)$. Analytical absorption correction with PLATON $^{58}$ ( $\mu=1.515 \mathrm{~mm}^{-1}, 0.67-0.89$ transmission). Structure solved with Patterson methods (DIRDIF-97) ${ }^{59}$ and refined with SHELXL- $97^{60}$ against $F^{2}$ of all reflections. Non-hydrogen atoms were refined freely with anisotropic displacement parameters. Hydrogen atoms were refined as rigid groups. 525 refined parameters, 7 restraints. $R$-values $[I>2 \sigma(I)]: R 1=$ $0.0357, w R 2=0.1201$. $R$-values [all reflections]: $R 1=0.0396$, $w R 2=0.1233$. Molecular illustration, structure checking and calculations were performed with the PLATON package. ${ }^{58}$

Crystal structure determination of 1c. $\mathrm{C}_{45} \mathrm{H}_{36} \mathrm{BrNOP}_{2} \mathrm{PdSi}$ $2 \mathrm{CH}_{2} \mathrm{Cl}_{2}, \mathrm{FW}=1052.94$, colourless plate, $0.50 \times 0.38 \times 0.13$ $\mathrm{mm}^{3}$, monoclinic, $P 2{ }_{1} / c$ (no. 14), $a=21.781(3), b=10.5595(13)$, $c=22.522(4) \AA, \beta=119.206(13)^{\circ}, V=4521.5(12) \AA^{3}, Z=4$, $\rho=1.547 \mathrm{~g} \mathrm{~cm}^{-3} .18205$ reflections were measured on an EnrafNonius CAD4T diffractometer with a rotating anode $(\lambda=$ $0.71073 \AA$ ) at a temperature of 150 (2) K. 10315 reflections were unique $\left(R_{\mathrm{int}}=0.0544\right)$. Absorption correction with PLATON ${ }^{58}$ (DELABS, $\mu=1.665 \mathrm{~mm}^{-1}, 0.55-0.86$ transmission). Structure solved with direct methods (SIR97) ${ }^{61}$ and refined with SHELXL- $97^{60}$ against $F^{2}$ of all reflections. Non-hydrogen atoms were refined freely with anisotropic displacement parameters. Hydrogen atoms were refined as rigid groups. 523 refined parameters, no restraints. $R$-values $[I>2 \sigma(I)]: R 1=$ $0.0527, w R 2=0.1021 . R$-values [all reflections]: $R 1=0.1077$, $w R 2=0.1256$. Molecular illustration, structure checking and calculations were performed with the PLATON package. ${ }^{58}$

Crystal structure determination of 1d. $\mathrm{C}_{45} \mathrm{H}_{34} \mathrm{BrNOP} 2 \mathrm{PdS}$. $\mathrm{CH}_{2} \mathrm{Cl}_{2}, \mathrm{FW}=969.97$, yellow plate, $0.27 \times 0.27 \times 0.09 \mathrm{~mm}^{3}$, orthorhombic, Pnma (no. 62), $a=18.4791(1), b=15.1534(1)$, $c=14.9257(1) \AA, V=4179.51(5) \AA^{3}, Z=4, \rho=1.541 \mathrm{~g} \mathrm{~cm}^{-3}$. 75073 reflections were measured on a Nonius KappaCCD diffractometer with a rotating anode $(\lambda=0.71073 \AA)$ at a temperature of $150(2)$ K. 4971 reflections were unique $\left(R_{\text {int }}=0.0591\right)$. Absorption correction with PLATON ${ }^{58}$ (MULABS, $\mu=1.691$ $\mathrm{mm}^{-1}, 0.77-0.86$ transmission). Structure solved with Patterson methods (DIRDIF-97) ${ }^{59}$ and refined with SHELXL-9760 against $F^{2}$ of all reflections. Non-hydrogen atoms were refined freely with anisotropic displacement parameters. Hydrogen atoms were refined as rigid groups. 523 refined parameters, no restraints. $R$-values $[I>2 \sigma(I)]: R 1=0.0267, w R 2=0.0675$. $R$-values [all reflections]: $R 1=0.0307, w R 2=0.0693$. Molecular illustration, structure checking and calculations were performed with the PLATON package. ${ }^{58}$

Crystal structure determination of $2 \mathbf{b} . \mathrm{C}_{40} \mathrm{H}_{35} \mathrm{OP}_{2} \mathrm{ClPd} \cdot$ $\mathrm{C}_{4} \mathrm{H}_{10} \mathrm{O}, \mathrm{FW}=735.5$, yellow cube, $0.20 \times 0.40 \times 0.60 \mathrm{~mm}^{3}$, 
monoclinic, $P 2_{1} / n, a=12.7823(9), b=17.954(1), c=16.961(2)$ $\AA, \beta=93.290(5)^{\circ}, V=3886.0(6) \AA^{3}, Z=4, \rho=1.380 \mathrm{~g} \mathrm{~cm}^{-3}$. 7967 reflections were measured on an Enraf-Nonius CAD-4 diffractometer $(\lambda=1.5418 \AA)$ at room temperature. Analytica absorption correction with the program ABSCAL (Watenpaugh and Stewart, 1992) using $\psi$-scans of the [-2 63 3] reflection, with coefficients in the range 1.0-3.04. The structure was solved with the PATTY option of the DIRDIF-96 program system. ${ }^{62}$ Non-hydrogen atoms were refined freely with anisotropic displacement parameters. Hydrogen atoms were calculated. $R$-values: $\left[(\Delta / \sigma)_{\max }=0.27, S=0.93\right]$ a weighting scheme $w=\left[10+0.001\left(\sigma\left(F_{\text {obs }}\right)\right)^{2}+0.0001 /\left(\sigma\left(F_{\text {obs }}\right)\right)\right]^{-1}$ was used $(R=$ $0.061, R_{w}=0.064$. All calculations were performed with XTAL, ${ }^{63}$ unless stated otherwise.

Crystal structure determination of $4 \mathbf{b} . \mathrm{C}_{46} \mathrm{H}_{36} \mathrm{BrNOP}_{2} \mathrm{Pd}$. $\mathrm{CF}_{3} \mathrm{SO}_{3} \cdot \mathrm{CH}_{2} \mathrm{Cl}_{2}, \mathrm{FW}=1021.09$, colourless block, $0.33 \times 0.33 \times$ $0.24 \mathrm{~mm}^{3}$, monoclinic, $P 2_{1} / n$ (no. 14), $a=13.2554(10), b=$ 22.3413(10), $c=15.0667(10) \AA, \beta=91.984(10)^{\circ}, V=4459.2(10)$ $\AA^{3}, Z=4, \rho=1.521 \mathrm{~g} \mathrm{~cm}^{-3} .82840$ reflections were measured on an Nonius KappaCCD diffractometer with a rotating anode $(\lambda=0.71073 \AA)$ at a temperature of $150(2) \mathrm{K}$. The crystal appeared to be non-merohedrically twinned with a two-fold rotation around $a^{*}$ as the twin operation. The evaluation of the data was performed with the program EVAL14 ${ }^{64}$ and the reflections were not merged. No absorption correction was applied. The structure was solved by Patterson methods (DIRDIF-97) ${ }^{59}$ and the non-overlapping reflections. The twin refinement was performed with SHELXL-97 ${ }^{60}$ against $F^{2}$ of all reflections using the HKLF5 option. ${ }^{65}$ Non-hydrogen atoms were refined freely with anisotropic displacement parameters. Hydrogen atoms were refined as rigid groups. 555 refined parameters, 62 restraints. $R$-values $[I>2 \sigma(I)]: R 1=0.0749, w R 2=0.1941$. $R$-values [all reflections]: $R 1=0.0956, w R 2=0.2163$. Molecular illustration, structure checking and calculations were performed with the PLATON package. ${ }^{58}$

Crystal structure determination of 5a. $\mathrm{C}_{39} \mathrm{H}_{34} \mathrm{NOP}_{2} \mathrm{Pd}$. $\mathrm{CF}_{3} \mathrm{SO}_{3}, \mathrm{FW}=850.1$, colourless cube, $0.20 \times 0.25 \times 0.30 \mathrm{~mm}^{3}$, monoclinic, $P 2_{1} / n, a=10.8261(6), b=26.801(2), c=13.8267(8)$ $\AA ̊ ㇒=109.637(9)^{\circ}, V=3778.5(5) \AA^{3}, Z=4, \rho=1.49 \mathrm{~g} \mathrm{~cm}^{-3}$. 7751 reflections were measured on an Enraf-Nonius CAD-4 diffractometer $(\lambda=1.5418 \AA)$ at $-20^{\circ} \mathrm{C}$. Analytical absorption correction with the program ABSCAL (Watenpaugh and Stewart 1992) using $\psi$-scans of the [0 14 6] reflection, with coefficients in the range 1.0-1.24. The structure was solved with the PATTY option of the DIRDIF-96 program system. ${ }^{62}$ Nonhydrogen atoms were refined freely with anisotropic displacement parameters. Hydrogen atoms were calculated. $R$-values: $\left[(\Delta / \sigma)_{\max }=0.54, S=1.12\right]$ a weighting scheme $w=[20+$ $\left.0.001\left(\sigma\left(F_{\text {obs }}\right)\right)^{2}+0.0001 /\left(\sigma\left(F_{\text {obs }}\right)\right)\right]^{-1}$ was used $\left(R=0.070, R_{w}=\right.$ 0.074 . All calculations were performed with XTAL, ${ }^{63}$ unless stated otherwise.

Crystal structure determination of 5 f-tBu. $\mathrm{C}_{27} \mathrm{H}_{47} \mathrm{FeP}_{2} \mathrm{Pd}$. $\mathrm{CF}_{3} \mathrm{SO}_{3}, \mathrm{FW}=744.91$, orange block, $0.33 \times 0.24 \times 0.15 \mathrm{~mm}^{3}$, monoclinic, $P 2_{1} / c$ (no. 14), $a=11.7515(1), b=16.9323(2)$, $c=16.8170(2) \AA, \beta=105.8589(6)^{\circ}, V=3218.88(6) \AA^{3}, Z=4$, $\rho=1.537 \mathrm{~g} \mathrm{~cm}^{-3} .53974$ reflections were measured on a Nonius KappaCCD diffractometer with a rotating anode $(\lambda=0.71073$ $\AA$ ) at a temperature of 150 (2) K. 7369 reflections were unique $\left(R_{\text {int }}=0.0459\right)$. Absorption correction with PLATON $^{58}$ (MULABS, $\mu=1.218 \mathrm{~mm}^{-1}, 0.75-0.82$ transmission). Structure solved with Patterson methods (DIRDIF-97) ${ }^{59}$ and refined with SHELXL-9 $7^{60}$ against $F^{2}$ of all reflections. Non-hydrogen atoms were refined freely with anisotropic displacement parameters. Hydrogen atoms were refined freely with isotropic displacement parameters. 540 refined parameters, no restraints. $R$-values $[I>2 \sigma(I)]: R 1=0.0249, w R 2=0.0561 . R$-values [all reflections]: $R 1=0.0323, w R 2=0.0587$. Molecular illustration, structure checking and calculations were performed with the PLATON package. ${ }^{58}$

Crystal structure determination of 6a. $\mathrm{C}_{39} \mathrm{H}_{31} \mathrm{O}_{3} \mathrm{~F}_{3} \mathrm{P}_{2} \mathrm{Pd}$, $\mathrm{FW}=772.98$, colourless cube, $0.30 \times 0.40 \times 0.50 \mathrm{~mm}^{3}$, triclinic, $P \overline{1}, a=10.976(1), b=11.516(1), c=15.503(5) \AA, a=98.14(1)$, $\beta=97.05(1), \gamma=113.89(1)^{\circ}, V=1738.2(7) \AA^{3}, Z=2, \rho=1.48 \mathrm{~g}$ $\mathrm{cm}^{-3}$. Final $R=0.078$ for 6886 observed reflections. 7751 reflections were measured on a Enraf-Nonius CAD-4 diffractometer $(\lambda=1.5418 \AA)$ at room temperature. Absorption correction was performed with the program PLATON ${ }^{58}$ following the method of North et al. using $\psi$-scans of five reflections, with coefficients in the range $0.630-0.978$. The structure was solved by the PATTY option of the DIRDIF-96 program system. ${ }^{62}$ Non-hydrogen atoms were refined freely with anisotropic displacement parameters. Hydrogen atoms were refined as rigid groups. The trifluoromethyl group was refined with a disorder model. $R$-values: [ $(\Delta / \sigma) \max =0.02, S=1.05]$ a weighting scheme $w \geq\left[\sigma^{2}\left(F_{\text {obs }}{ }^{2}\right)+(0.1266 P)^{2}+2.7287 P\right]^{-1}$ was used $(R=0.0642, w R 2=0.1761$ for $I>2 \sigma(I))$. All calculations were performed with SHELXL- $97^{60}$ unless stated otherwise.

CCDC reference numbers 133392-133394 and 177711177716.

See http://www.rsc.org/suppdata/dt/b1/b111596k/ for crystallographic data in CIF or other electronic format.

\section{Acknowledgements}

This work was supported (M. L., A. L. S.) by the Council for Chemical Sciences of the Netherlands Organisation for Scientific Research (CW-NOW) and by the Netherlands Ministry of Economic Affairs (grant EETK9710) (M. D. K. B., G. P. F. v. S.) The help of A. M. M. Schreurs in handling the twinned structure $\mathbf{4 b}$ is kindly acknowledged.

\section{References}

1 B. Cornils and W. A. Herrmann, in Applied Homogeneous Catalysis with Organometallic Compounds: A Comprehensive Handbook in Two Volumes, B. Cornils and W. A. Hermann, ed., VCH Publishers, New York, 1996.

2 C. A. Tolman, Chem. Rev., 1977, 77, 313-348.

3 C. P. Casey and G. T. Whiteker, Isr. J. Chem., 1990, 30, 299.

4 P. C. J. Kamer, J. N. H. Reek and P. W. N. M. van Leeuwen, CHEMTECH, 1998, 27-33.

5 R. F. Heck, Palladium Reagents in Organic Syntheses, Academic Press, New York, 1985.

6 L. S. Hegedus, Organometallics in Synthesis, Wiley, New York, 1994.

7 E. Negishi, Acc. Chem. Res. 1982, 15, 340.

8 J. K. Stille, Angew. Chem., Int. Ed. Engl., 1986, 25, 508

9 A. Suzuki, Acc. Chem. Res., 1982, 15, 178.

10 J. F. Hartwig, Angew. Chem., Int. Ed., 1998, 37, 2046-2067.

11 B. M. Trost and D. L. van Vranken, Chem. Rev., 1996, 96, 395-422.

12 P. S. Pregosin and R. Salzmann, Coord. Chem. Rev., 1996, 155, 35-68.

13 E. Drent and P. H. M. Budzelaar, Chem. Rev., 1996, 96, 663-681.

14 A. Sommazzi and F. Garbassi, Prog. Polym. Sci., 1997, 22, 1547.

15 R. F. Heck, Acc. Chem. Res., 1979, 146-151.

16 R. F. Heck, Org. React., 1982, 27, 345-390.

17 W. Cabri and I. Candiani, Acc. Chem. Res., 1995, 28, $2-7$.

18 A. de Meijere and F. E. Meyer, Angew. Chem., Int. Ed. Engl., 1994, 33, 2379-2411

19 H. Werner, G. T. Crisp, P. W. Jolly, H.-J. Kraus and C. Krüger, Organometallics, 1983, 2, 1369-1377.

20 V. V. Bashilov, P. V. Petrovskii, V. I. Sokolov, S. V. Lindeman, I. A. Guzey and Y. T. Struchkov, Organometallics, 1993, 12, 991992.

21 K. Okamoto, Y. Kai, N. Yasuoka and N. Kasai, J. Organomet. Chem., 1974, 65, 427-441.

22 M. Hodgson, D. Parker, R. J. Taylor and G. J. Ferguson, J. Chem. Soc., Chem. Commun., 1987, 1309-1311.

23 R. Benn, P. Betz, R. Goddard, P. W. Jolly, N. Kokel, C. Krüger and I. Z. Topalovic, Z. Naturforsch., Teil B, 1991, 46, 1395-1405.

24 W. A. Herrmann, W. R. Thiel, C. Brossmer, K. Öfele, T. Priermeier and W. J. Scherer, J. Organomet. Chem., 1993, 461, 51-60. 
25 M. Kranenburg, Y. E. M. van der Burgt, P. C. J. Kamer, P. W. N. M. van Leeuwen, K. Goubitz and J. Fraanje, Organometallics, 1995, 14, 3081.

26 L. A. van der Veen, P. H. Keeven, G. C. Schoemaker, J. N. H. Reek, P. C. J. Kamer, P. W. N. M. van Leeuwen, M. Lutz and A. L. Spek, Organometallics, 2000, 19, 872-883.

27 P. W. N. M. van Leeuwen, P. C. J. Kamer, J. N. H. Reek and P. Dierkes, Chem. Rev., 2000, 100, 2741-2770.

28 M. Kranenburg, P. C. J. Kamer and P. W. N. M. van Leeuwen, Eur. J. Inorg. Chem., 1998, 25-27.

29 R. J. van Haaren, H. Oevering, B. B. Coussens, G. P. F. van Strijdonck, J. N. H. Reek, P. C. J. Kamer and P. W. N. M. van Leeuwen, Eur. J. Inorg. Chem., 1999, 1237-1241.

30 M. Kranenburg, P. C. J. Kamer and P. W. N. M. van Leeuwen, Eur. J. Inorg. Chem., 1998, 155.

31 M. S. Goedheijt, J. N. H. Reek, P. C. J. Kamer and P. W. N. M. van Leeuwen, Chem. Commun., 1998, 2431-2432.

32 M. Kranenburg, P. C. J. Kamer, P. W. N. M. van Leeuwen, D. Vogt and W. Keim, J. Chem. Soc., Chem. Commun., 1995 2177.

33 M. Kranenburg, J. G. P. Delis, P. C. J. Kamer, P. W. N. M. van Leeuwen, K. Vrieze, N. Veldman, A. L. Spek, K. Goubitz and J. Fraanje, J. Chem. Soc., Dalton Trans., 1997, 1839.

34 G. Dube, D. Selent and R. Taube, Z. Chem., 1985, 25, 154.

35 J. J. Bishop, A. Davison, M. L. Katcher, D. W. Lichtenberg, R. E. Merrill and J. C. Smart, J. Organomet. Chem., 1971, 22 , 241.

36 R. A. Widenhoefer, H. A. Zhong and S. L. Buchwald, J. Am. Chem. Soc., 1997, 119, 6787-6795.

37 L. Ludwig, S. Stromberg, M. Swensson and B. Akermark, Organometallics, 1999, 18, 970-975.

38 G. P. C. M. Dekker, C. J. Elsevier, K. Vrieze and P. W. N. M. van Leeuwen, Organometallics, 1992, 11, 1598-1603.

39 V. Dufaud, J. Thivolle-Cazat, J.-M. Basset, R. Mathieu, J. Jaud and J. Waisserman, Organometallics, 1991, 10, 4005-4015.

40 A. Bohm, K. Polborn, K. Sunkel and W. Beck, Z. Naturforsch., Teil B, 1998, 53, 448.

41 W. A. Herrmann, C. Brossmer, T. H. Riermeier and K. Öfele, J. Organomet. Chem., 1994, 481, 97-108.

42 I. R. Butler, L. J. Hobson, S. J. Coles, M. B. Hurthouse and K. M. Abdul Malik, J. Organomet. Chem., 1997, 540, 27-40.

43 H. Trauner, P. le Floch, J.-M. Lefour, L. Ricard and F. Mathey, Synthesis, 1995, 717-726.

44 J. M. Brown, J. J. Perez-Torrente, N. W. Alcock and H. J. Clase, Organometallics, 1995, 14, 207-213.

45 M. Tschoerner and P. S. Pregosin, Organometallics, 1999, 18 670-678.

46 J. G. P. Delis, P. W. N. M. van Leeuwen, K. Vrieze, N. Veldman, A. L. Spek, J. Fraanje and K. Goubitz, J. Organomet. Chem., 1996, 514, 125-136.
47 P. K. Byers, A. J. Canty, B. W. Skelton and A. H. White, J. Organomet. Chem., 1987, 336, C55-C60.

48 M. J. Green, G. J. P. Britovsek, K. J. Cavell, B. W. Skelton and A. H. White, J. Chem. Soc., Chem. Commun., 1996, 1563-1564.

49 M. W. Haenel, D. Jakubik, C. Krueger and P. Betz, Chem. Ber., 1991, 124, 333-336.

50 Preliminary spectroscopic data on the palladium complexes containing f-tBu have been published, M. A. Zuideveld, B. H. G. Swennenhuis, P. C. J. Kamer and P. W. N. M. van Leuwen, J. Organomet. Chem., 2001, 637-639, 805-808.

51 M. Sato, H. Shigeta, M. Sekino and S. Akabori, J. Organomet. Chem., 1993, 458, 199-204.

52 M. Sato, K. Suzuki, H. Asano, M. Sekino, Y. Kawata, Y. Habata and S. Akabori, J. Organomet. Chem., 1994, 470, 263.

53 P. Dierkes and P. W. N. M. van Leeuwen, J. Chem. Soc., Dalton Trans., 1999, 1519-1529.

54 (a) A. Magistrato, M. Merlin, P. S. Pregosin, U. Rothlisberger and A. Albinati, Organometallics, 2000, 19, 3591-3596; (b) A. Magistrato, P. S. Pregosin, A. Albinati and U. Rothlisberger, Organometallics, 2001, 20, 4178-4184.

55 L. V. Andreasen, O. Simonsen and O. Wernberg, Inorg. Chim. Acta, 1999, 153-163; L. V. Andreasen, O. Simonsen and O. Wernberg, Inorg. Chim. Acta, 1999, 295, 153-163.

56 A. L. Boyes, I. R. Butler and S. C. Quayle, Tetrahedron Lett., 1998, 39, 7763-7766.

57 S. J. Young, B. Kellenberger, J. H. Reibenspies, S. E. Himmel, M. Manning, O. P. Anderson and J. K. Stille, J. Am. Chem. Soc., 1988, 110, 5744-5753

58 A. C. T. North, D. C. Phillips and F. Scott Mathews, Acta Crystallogr., Sect. A, 1968, 26, 351-359.

59 P. T. Beurskens, G. Admiraal, G. Beurskens, W. P. Bosman, S. Garcia-Granda, R. O. Gould, J. M. M. Smits and C. Smykalla, The DIRDIF-97 program system, Technical Report of the Crystallography Laboratory, University of Nijmegen, The Netherlands, 1997.

60 G. M. Sheldrick, SHELXL-97, Program for crystal structure refinement, University of Göttingen, Germany, 1997.

61 A. Altomare, M. C. Burla, M. Camalli, G. L. Cascarano, G. Giacovazzo, A. Guagliardi, A. G. G. Moliterni, G. Polidori and R. Spagna, J. Appl. Crystallogr. 1999, 32, 115-119.

62 P. T. Beurskens, G. Beurskens, W. P. Bosman, R. de Gelder, S. Garcia-Granda, R. O. Gould, R. Israel and J. M. M. Smits, The DIRDIF-96 program system, Crystallography Laboratory, University of Nijmegen, The Netherlands 1996.

63 S. R. Hall, G. S. D. King and J. M. Stewart, eds., XTAL3.4 User's Manual, University of Western Australia, Lamb, Perth, 1995.

64 A. J. M. Duisenberg, PhD thesis, Utrecht University, The Netherlands, 1998.

65 R. Herbst-Irmer and G. M. Sheldrick, Acta Crystallogr., Sect. B, 1998, 54, 443-449. 